\title{
Room temperature reduction of nitrogen oxide to nitrogen on Metal-
}

\section{Organic Frameworks}

Marco Daturi ${ }^{1 *}$, Vanessa Blasin-Aubé ${ }^{1}$, Ji Wong Yoon ${ }^{1,2}$, Philippe Bazin ${ }^{1}$, Alexandre Vimont $^{1}$, Jong-San Chang ${ }^{2,3}$, Young Kyu Hwang ${ }^{2}$, You-Kyong Seo ${ }^{2}$, Seunghun Jang ${ }^{2}$, Hyunju Chang ${ }^{2}$, Stefan Wuttke ${ }^{1,4}$, M. Haneda ${ }^{4}$, Patricia Horcajada ${ }^{5}$, Christian Serre ${ }^{5}$

${ }^{1}$ Normandie Univ., ENSICAEN, UNICAEN, CNRS, Laboratoire Catalyse et Spectrochimie, 14000 Caen, France.

${ }^{2}$ Catalysis Center for Molecular Engineering, Korea Research Institute of Chemical Technology (KRICT); Jang-dong 100, Yuseong, Daejeon 305-600, South Korea.

${ }^{3}$ Department of Chemistry, Sungkyunkwan University, Suwon 440-476, South Korea.

${ }^{4}$ Nagoya Inst. Technol., Grad. Sch. Engn., Dept. Frontier Mat., Showa Ku, Nagoya, Aichi 4668555, Japan

${ }^{5}$ Institut Lavoisier (UMR CNRS 8180), Université de Versailles Saint-Quentin-en-Yvelines, 45, avenue des Etats-Unis, 78035 Versailles, Université Paris Saclay, France. Present address: Ecole Normale Supérieure, Ecole Supérieure de Physique et de Chimie Industrielles de Paris, Paris Sciences Letter University, 75005 Paris, France

\begin{abstract}
Air pollution is an epochal concern, particularly in urban areas, and is linked to combustion processes $^{1}$. The emission of nitrogen oxides (NOx) constitutes a critical environmental problem, and it can affect severely human health ${ }^{2,3,4}$. At ambient temperature and pressure NOx decomposition is thermodynamically favoured; however, this process is kinetically inhibited, owing to a high activation energy $y^{5,6}$. To date, no reported catalysts have had the required properties to lower the activation energy of this process without the help of coreacting agents and high temperatures ${ }^{7,8,9}$. Here, we show that NO conversion to molecular nitrogen can be achieved at room temperature in the presence of $\mathrm{O}_{2}$ and $\mathrm{H}_{2} \mathrm{O}$ vapour, and in the absence of any further reducing agent, using iron-based Metal-Organic Frameworks (MOFs). Further, we demonstrate that MOFs work similarly to enzymes, but are stable in environments unfriendly to living matter. These findings open large perspectives on the solution of stringent problems in chemistry, such as the removal of pollutants or the activation of highly stable molecules.
\end{abstract}




\section{Introduction}

The inorganic nitrogen cycle is the process by which nitrogen, in various chemical forms, is circulated by a continuous natural cycle ${ }^{10}$. Human activities in the modern industrial society have caused serious and diverse environmental problems, including interference with the nitrogen cycle both in aqueous and atmospheric environments. Although various methods have been adopted to reduce NOx selectively ${ }^{11}$, some aspects of these technologies are still underdeveloped and further progress is still needed to overcome their drawbacks and cost limitations ${ }^{12}$. The daunting challenge to remove NOx in a sustainable way is to find a catalyst that is able to favour the decomposition reaction without being poisoned by oxygen ${ }^{13}$, i.e. a catalyst ideally working at room temperature like enzymes, without the necessity of reducing agents. Denitrification in nature is based on an assortment of different enzymes that sequentially reduce nitrate to dinitrogen via nitrogen oxide intermediates, e.g., nitrate reductase, nitrite reductase (NIR), nitric oxide reductase (NOR) and nitrous oxide reductase. These enzymes are mainly iron and copper based metalloenzymes ${ }^{10,14}$. However, enzymes are generally unstable out of aqueous solutions and therefore cannot be applied directly for the purification of polluted gases. Conversely, heterogeneous catalysts investigated to date are unable to imitate enzyme mechanisms, still requiring oxygen scavengers and/or high temperatures of reaction ${ }^{11,15,16}$. In fact, the active site environment in the metalloenzyme complexes is highly specific, as the result of million years of evolution. Catalysts that are intended to mimic enzyme mechanisms should therefore have a similar configuration ${ }^{10,14,17}$. The reduction of nitrites by heme- $c d_{1}$ is proposed to proceed via the binding of a nitrite to the reduced $\mathrm{Fe}^{\mathrm{II}}$ centre with a concomitant dehydration/oxidation reaction to yield a putative 'oxidized' Fe ${ }^{\mathrm{III}}$-NO moiety. The active site of cNOR contains a heme/non-heme diiron centre, where the reduction of the diiron site weakens the oxo bridge and favours the coordination of two NO molecules. The NO molecules are coordinated in close enough proximity to destabilise these otherwise poorly reactive complexes and promotes the formation of a N-N bond $^{14}$. With these examples in mind, we focused our attention on the mesoporous iron(III) trimesate MIL-100(Fe) (MIL stands for Materials from Institut Lavoisier) or $\left[\mathrm{Fe}_{3} \mathrm{O}\left(\mathrm{H}_{2} \mathrm{O}\right)_{2} \mathrm{~F}_{0.81}(\mathrm{OH})_{0.19}\left\{\mathrm{C}_{6} \mathrm{H}_{3}\left(\mathrm{CO}_{2}\right)_{3}\right\}_{2} \cdot n \mathrm{H}_{2} \mathrm{O} \quad(n \approx 14.5)\right]$ as a possible candidate for the development of a new NOx removal (DeNOx) catalyst. MIL-100(Fe) is a hydrothermally stable MOF built up from oxo-centred trimers of iron(III) octahedra interconnected by 1,3,5benzene tricarboxylate linkers giving rise to a mesoporous zeotype architecture (Fig. 1) ${ }^{18}$. 


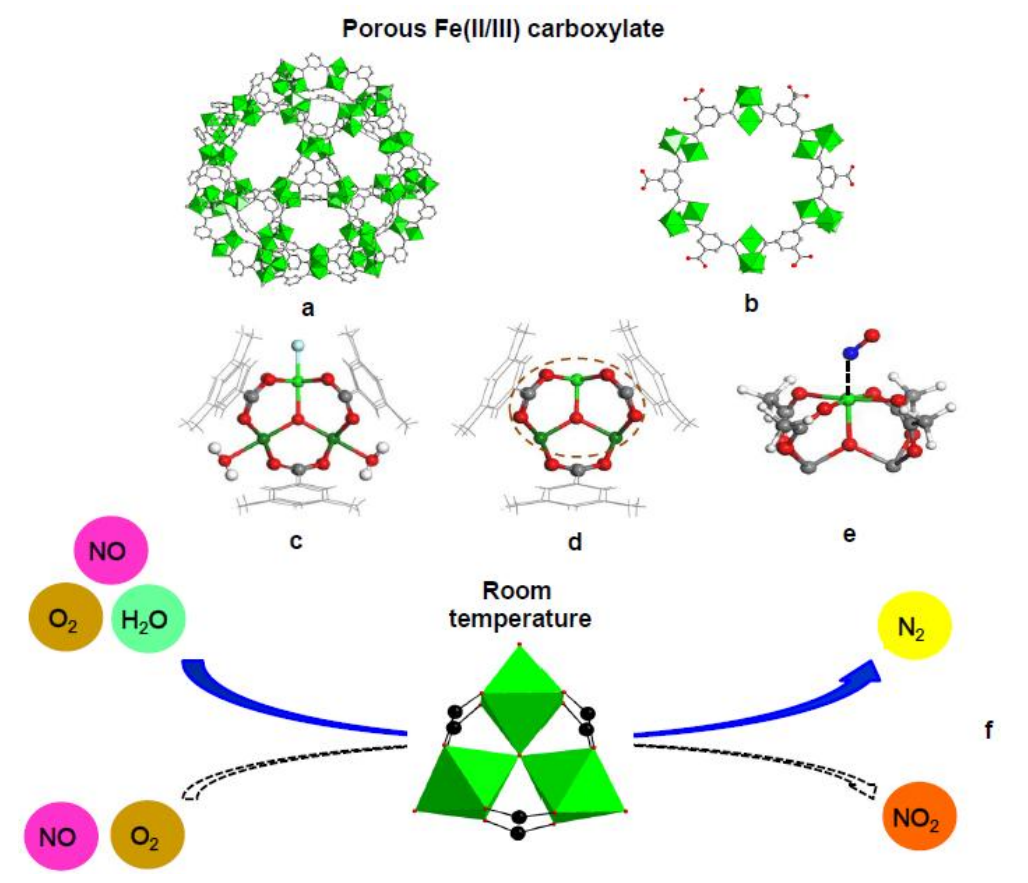

Figure 1: Schematic representation of the iron trimesate MIL-100(Fe) and the binding of NO over the iron metal sites. a, a mesoporous cage of MIL-100(Fe). b, A porous cage of MIL$100(\mathrm{Fe})$. c, View of one hydrated trimer of iron(III) octahedra. d, One dehydrated and defluorinated trimer of iron(II, III) octahedra. e, Coordination of one NO molecule over one $\mathrm{Fe}(\mathrm{II}) / \mathrm{Fe}$ (III) model cluster. f, Scheme of reaction behaviours on a mixed valent $\mathrm{Fe}^{\mathrm{II}} / \mathrm{Fe}^{\mathrm{III}}$ trimer for the $\mathrm{NO} / \mathrm{O}_{2}$ and the $\mathrm{NO} / \mathrm{O}_{2} / \mathrm{H}_{2} \mathrm{O}$ mixtures at room temperature.

We have previously shown that this solid exhibits accessible $\mathrm{Fe}^{\mathrm{II}}$ and $\mathrm{Fe}^{\mathrm{III}}$ coordinatively unsaturated metal sites upon thermal activation at $523 \mathrm{~K}^{19}$. Within each trimer of MIL$100(\mathrm{Fe})$, one $\mathrm{Fe}^{\mathrm{II}}$ site is surrounded by at least one $\mathrm{Fe}^{\mathrm{III}}$ site, imitating the unique environment observed in iron clusters of active NO reductive metalloenzymes, being this environment also indicated by preliminary density functional theory (DFT) calculations (see SI - Supplementary Information). This unusual property, which is specific to all Fe carboxylate-based MOFs built up from the same trimeric building unit ${ }^{20}$, has been used to enhance the separation of hydrocarbons ${ }^{19}$, and led to an improvement of the controlled release of NO as a biological $\operatorname{gas}^{21}$.

\section{Results and Discussion}

MIL-100(Fe) was initially treated under argon for $5 \mathrm{~h}$ at $523 \mathrm{~K}$ to create $\mathrm{Fe}^{\mathrm{II}} / \mathrm{Fe}^{\mathrm{III}}$ pairs in the trimer moieties (with a $\mathrm{Fe}^{\mathrm{II}} / \mathrm{Fe}^{\mathrm{III}}$ ratio $=c a$. 0.3), as confirmed by in-situ IR spectroscopic analysis $^{22}$, UV-vis analysis and even XAS data. The DeNOx reaction at $300 \mathrm{~K}$ was tested using a wafer of casted MIL-100(Fe) powder to monitor the material in action spectroscopically under a gas reaction flow (gas hourly space velocity, GHSV $=5000 \mathrm{~h}^{-1}$ ) 
typically containing $1000 \mathrm{ppm} \mathrm{NO}, 10 \% \mathrm{O}_{2}$, and $1 \% \mathrm{H}_{2} \mathrm{O}$. For the sake of clarity, Ccontaining impurities such as $\mathrm{CO}_{2}, \mathrm{CO}$ and hydrocarbons were carefully eliminated in the feed mixture. To our surprise, we found that up to $13 \%$ of the feed NO was catalytically and selectively converted to $\mathrm{N}_{2}$ in the presence of $\mathrm{O}_{2}$ and $\mathrm{H}_{2} \mathrm{O}$ vapour, without any reducing agent. The resulting IR spectra of the catalyst under flow are presented in Fig. 2 a \& b, where the adsorbed species evolving versus time are illustrated (Fig. 2c).
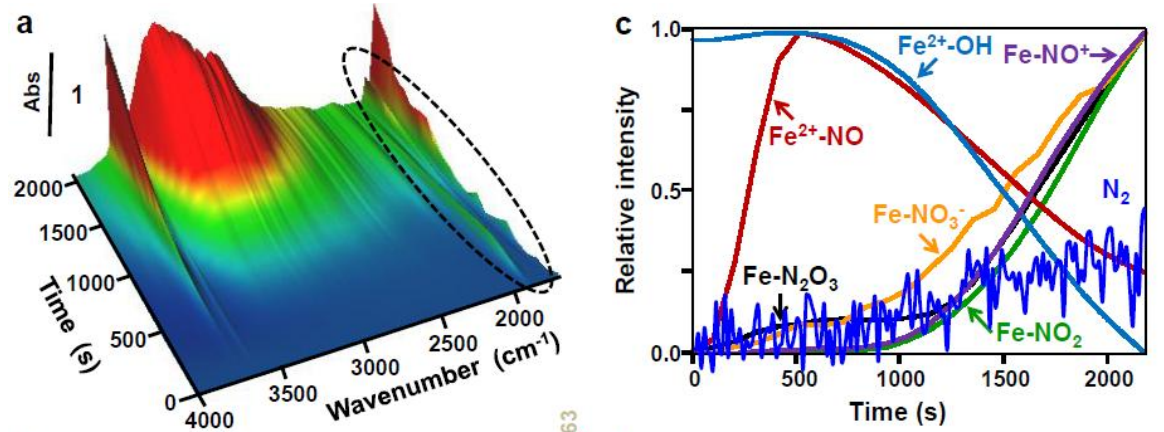

b

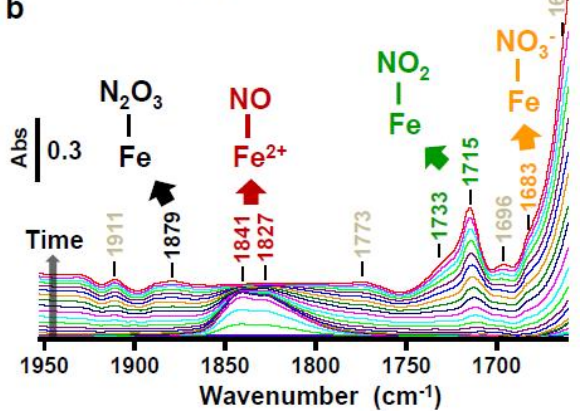

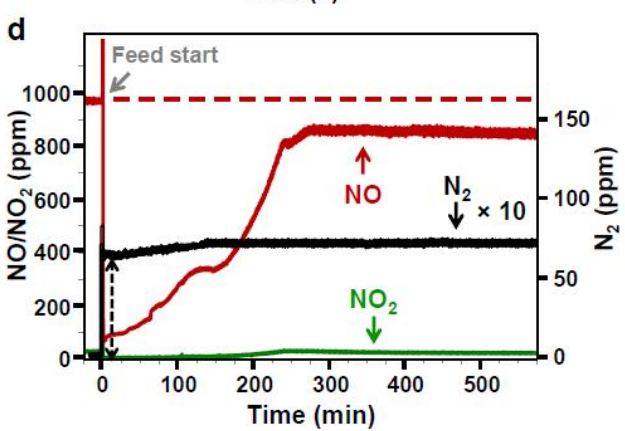

Figure 2: Surface and gas species during NO decomposition. a, 3D view of the transmission FTIR spectra in the vibrational MID-IR region of the MIL-100(Fe) sample activated at $523 \mathrm{~K}$, then submitted to the reaction stream at $298 \mathrm{~K}$. b, Waterfall of spectra (zoomed in the dotted region and subtracting the first spectrum in the series) collected every $105 \mathrm{~s}$ and during 2185 $\mathrm{s}$, after about $33 \mathrm{~min}$ from $\mathrm{t}_{0}$. They present only the modification of the material vibrations and of the adsorbed species. c, Intensity profiles versus time for the main species present on the surface of MIL-100(Fe) submitted to the reaction flow. The timeline is coherent with the spectra in Fig. 2b. d, Gas phase profiles for N-containing species during reaction, using $\mathrm{Kr}$ as an internal standard for the quantification of the species measured by a mass spectrometer.

Two phenomena appeared since the beginning: NO absorption by the sample and nitrogen production. While the first was protracted over a few hours (due to the large absorption capacity of the material ${ }^{23}$ ), the second rapidly reached a steady state (Fig. 2d). The selective formation of $\mathrm{N}_{2}$ was confirmed by both the $\mathrm{m} / \mathrm{z}=28$ signal observed by mass spectrometry and the absence of any other detectable N-containing species. Noteworthy, in a classical plug flow reactor NOx conversion was higher, reaching for example $34 \%$ at GHSV $15,000 \mathrm{~h}^{-1}$, as detailed in SI; however, in order to get information on the gas phase and the catalyst behaviour simultaneously, we focus on the operando results. 
The DeNOx reaction takes place only when $\mathrm{Fe}^{\mathrm{II}}$ species are present, as indicated by the doublet IR peaks at 1841 and $1827 \mathrm{~cm}^{-1}$ (Fig. 2c), typical of $\mathrm{Fe}^{\mathrm{II}}$-nitrosyls ${ }^{19}$. In fact, when the sample was activated at $423 \mathrm{~K}$, no $\mathrm{Fe}^{\mathrm{II}}$ sites were detected via the adsorption of probe molecules and, consequently, no reactivity could be observed (Fig. 3b). However, upon further activation of this sample at $523 \mathrm{~K}, \mathrm{Fe}^{\mathrm{II}}$ species were clearly evidenced by IR spectroscopy, and the NO conversion activity was observed, as previously shown in Figs. 2. Thus, the catalytic activity of MIL-100(Fe) is unambiguously related to the presence of $\mathrm{Fe}^{\mathrm{II}}$ sites. Furthermore, the presence of oxygen and water in the gas flow is essential for the DeNOx reaction (Fig. 3 and SI), which could allow us to gain an understanding into the mechanism operating here.

a

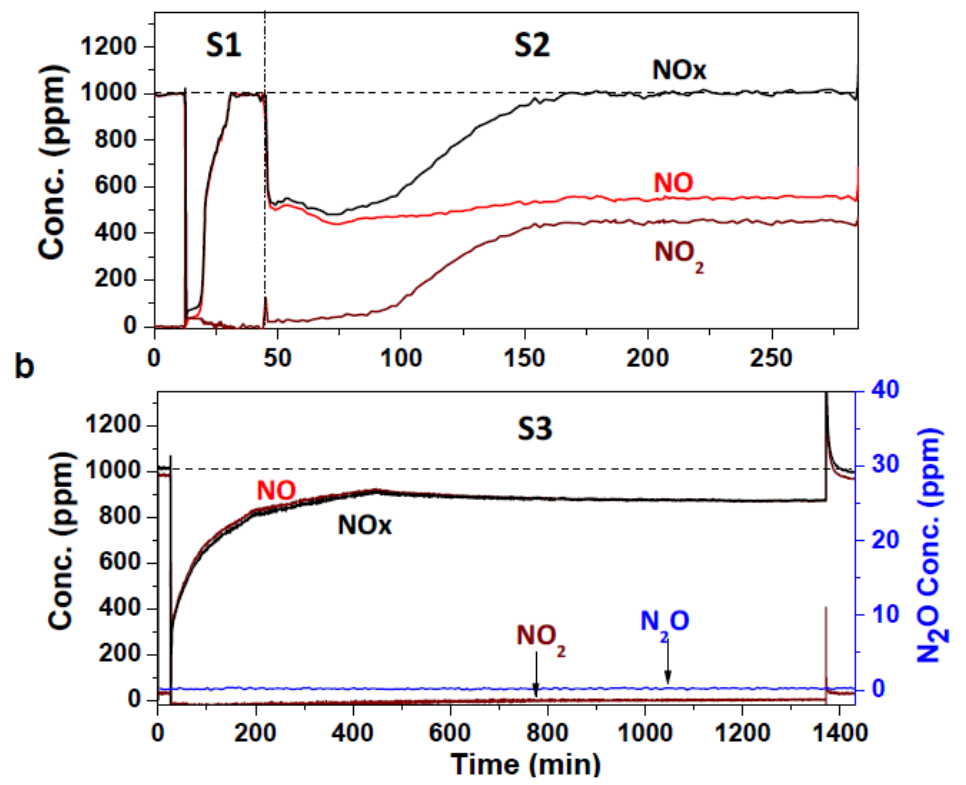

Figure 3: Effect of the gas composition on the catalytic reaction. Main species profiles in the gas phase after contact with partially reduced MIL-100(Fe) sample at $298 \mathrm{~K}$. a Sequential gas feeding with $1000 \mathrm{ppm} \mathrm{NO}$ (S1) followed by $1000 \mathrm{ppm} \mathrm{NO}$ with $10 \% \mathrm{O}_{2}$ (S2), and b, 1000 ppm $\mathrm{NO}, 10 \% \mathrm{O}_{2}$ and $1 \% \mathrm{H}_{2} \mathrm{O}$ vapour (S3). The profiles of $\mathrm{NO}$ and $\mathrm{NO}_{2}$ were measured by NOx analyser, while the profile of $\mathrm{N}_{2} \mathrm{O}$ was collected by an IR gas analyser.

Obviously, detailed comprehension of the mechanism of $\mathrm{NO}$ reduction into $\mathrm{N}_{2}$ on MIL$100(\mathrm{Fe})$ (beyond the scope of the present study) would require further extensive and dedicated investigations. The reactions involved in DeNOx are extremely complex, and the proposed mechanisms are still under debate ${ }^{11}$, even after decades of investigation. Nevertheless, some of our spectroscopic evidences highlight the formation of adsorbed species (see SI and Extended Data Figure 9) which can be related to those proposed for the reduction of nitrites by the heme $\mathrm{cd}_{1}$-containing $\mathrm{NIR}^{10}$ and for the $\mathrm{NOR}^{14}$ in fungal and bacterial enzymes. The 
latter, in particular, have the active structure that consists of a binuclear oxo-bridged heme/non-heme iron active site, in which the $\mu$-oxo-bridged $\mathrm{Fe}-\mathrm{O}-\mathrm{Fe}$ moiety has a $\mathrm{Fe}-\mathrm{Fe}$ distance of $3.5 \AA$ and a (Fe-O-Fe) angle of $145^{\circ}{ }^{14}$. In MIL-100(Fe), the distance between the two iron sites in the trimers is close to $3.4 \AA$ with a (Fe-O-Fe) angle of $120^{\circ}$. These structural similarities allow us to postulate a common mechanism between enzymatic catalysis and NO removal by MOFs, where the organic-inorganic hybrid structure of MIL-100(Fe) would behave as a solid homologue of the organometallic cluster at the core of the NOR. This would explain the slow measured reactivity, which is a typical feature of enzymatic driven mechanisms ${ }^{10}$. Similar conclusions have been proposed recently to explain selective catalytic reduction of NOx with $\mathrm{NH}_{3}$ on $\mathrm{Cu}$-exchanged SSZ-13 zeolites ${ }^{24}$ as well as oxidation phenomena of ethane with $\mathrm{N}_{2} \mathrm{O}$, observed on the microporous iron hydroxyterephthalate MOF-74 or CPO-27(Fe ${ }^{25}$. However, in the latter case the presence of monomeric $\mathrm{Fe}^{\mathrm{II}}$ sites in the CPO-27 structure makes this material likely unsuitable for DeNOx reaction, besides the fact that this material also suffers from instability towards water and oxygen.

If the hypothesised mechanism requires the presence of neighbouring $\mathrm{Fe}^{\mathrm{II}} / \mathrm{Fe}^{\mathrm{III}}$ unsaturated sites, other iron carboxylate analogues should also be active towards NO conversion at room temperature. Significantly, the microporous iron 3,3',5,5'-azobenzenetetracarboxylate MIL$127(\mathrm{Fe})$ solid, that exhibits the same constitutive iron trimers, showed a similar reactivity (see SI). Conversely, the iron 1,4,5,8-naphthalentetracarboxylate MIL-102(Fe) solid based on the same trimers but exhibiting very narrow pores $(<4 \AA)$, and the flexible microporous iron terephthalate MIL-53(Fe) solid containing a different building unit with no accessible metal sites (see SI), were both inactive for the DeNOx reaction. This indicates that the combination of iron trimers and pore accessibility is a prerequisite for NO transformation under ambient conditions.

\section{Conclusions and Outlook}

Our strategy therefore proposes the use of stable highly porous iron carboxylates bearing both accessible $\mathrm{Fe}^{\mathrm{II}}$ and $\mathrm{Fe}^{\mathrm{III}}$ sites as catalytic materials to decompose NOx at room temperature without any reducing agent. This strategy can potentially lead to major breakthroughs in the particular domain of NOx removal and represents a concrete progress in the use of MOFs as a new class of heterogeneous catalysts. Probably they will never been able to stand the extreme conditions of an automotive exhaust, but they could be used for NOx abatement in confined polluted ambient, such as undergrounds parking, tunnels, factories, etc. But the most important is our proof of concept: conceptually, we are on the way to demonstrate that MOFs 
are a class of materials that bridge the gap between homogeneous (enzymatic) and heterogeneous (solid) catalysis by mimicking organometallic compounds. The iron-based MOFs proposed in this work are stable in the presence of moisture, relatively inexpensive to be industrially synthesised ${ }^{26,27}$, easily recyclable, and bio-compatible ${ }^{28}$, and are therefore likely to pave the way for new generations of highly efficient and sustainable catalysts ${ }^{29}$. In perspective, MOFs-based catalysts can face different challenging problems such as VOC abatement, light alkanes or $\mathrm{CO}_{2}$ activation, upon an appropriate rational tailoring.

\section{References}

\footnotetext{
${ }^{1}$ Buchholz, S. et al. Air pollution characteristics associated with mesoscale atmospheric patterns in northwest continental Europe. Atmos. Environ. 44, 5183-5190 (2010).

${ }^{2}$ Samoli, E. et al. Short-term effects of nitrogen dioxide on mortality: an analysis within the APHEA project. Eur. Respir. J. 27, 1129-1137 (2006).

${ }^{3}$ Peters, A. et al. Air pollution and incidence of cardiac arrhythmia. Epidemiology 11, 11-17 (2000).

${ }^{4}$ Arden Pope, C. III et al. Cardiovascular mortality and long-term exposure to particulate air pollution: Epidemiological evidence of general pathophysiological pathways of disease. Circulation 109, 71-77 (2004).

${ }^{5}$ Fritz, A. \& Pitchon, V. The current state of research on automotive lean NOx catalysis. Appl. Catal. B: Environmental 13, 1-25 (1997).

${ }^{6}$ Gomez-Garcia, M.A., Pitchon, V. \& Kiennemann, A. Pollution by nitrogen oxides: an approach to NO(x) abatement by using sorbing catalytic materials. Environment International 31, 445-467 (2005).

${ }^{7}$ Hamada, H., Kintaichi, Y., Sasaki, M. \& Ito, T. Sulfate-promoted metal oxide catalysts for the selective reduction of nitrogen monoxide by propane in oxygen-rich atmosphere. Chem. Lett. 20, 2179-2182 (1991).

${ }^{8}$ Haneda, M., Kintaichi, Y., Bion, N. \& Hamada, H. Alkali metal-doped cobalt oxide catalysts for NO decomposition. Appl. Catal. B: Environmental 46, 473-482 (2003).

${ }^{9}$ Neyertz, C., Volpe, M.A. \& Gigola, C. Palladium-vanadium interaction in binary supported catalysts. Catal. Today 57, 255-260 (2000).

${ }^{10}$ Averill, B.A. Dissimilatory nitrite and nitric oxide reductases. Chem. Rev. 96, 2951-2964 (1996).

${ }^{11}$ Granger, P. \& Parvulescu, V.I. Catalytic NOx abatement systems for mobile sources : From three-way to lean burn after-treatment technologies. Chem. Rev. 111, 3155-3207 (2011).

${ }^{12}$ Klingstedt, F., Arve, K., Eränen, K. \& Murzin, D.Y. Toward improved catalytic low-temperature NOx removal in diesel-powered vehicles. Acc. Chem. Res. 39, 273-282 (2006).

${ }^{13}$ Amirnazmi, A., Benson, J.E., \& Boudart, M. Oxygen inhibition in the decomposition of NO on metal oxides and platinum. J. Catal. 30, 55-65 (1973).

${ }^{14}$ Wasser, I.M. et al. Nitric oxide in biological denitrification: Fe/Cu metalloenzyme and metal complex NOx redox chemistry. Chem. Rev. 102, 1201-1234 (2002).

${ }^{15}$ Iwamoto, M. \& Hamada, M. Removal of nitrogen monoxide from exhaust gases through novel catalytic processes. Catal. Today 10, 57-71 (1991).

${ }^{16}$ Shelef, M. Selective Catalytic Reduction of NO, with N-Free Reductants. Chem. Rev. 95, 209-225 (1995).

${ }^{17}$ Ford, P.C. \& Lorkovic, I.M. Mechanistic Aspects of the Reactions of Nitric Oxide with Transition-Metal Complexes. Chem. Rev. 102, 993-1017 (2002).

${ }^{18}$ Horcajada, P. et al. Synthesis and catalytic properties of MIL-100(Fe), an iron(III) carboxylate with large pores. Chem. Commun. 2820-2822 (2007).

${ }^{19}$ Wuttke, S. et al. Discovering the active sites for $C_{3}$ separation in MIL-100(Fe) by using operando IR spectroscopy. Chem. Eur. J. 18, 11959-11967 (2012).

${ }^{20}$ Devic, T. \& Serre, C. High valence 3p and transition metal based MOFs. Chem. Soc. Rev. 43, 6097-6115 (2014).

${ }^{21}$ McKinlay, A.C. et al. Nitric oxide adsorption and delivery in flexible MIL-88(Fe) metal-organic frameworks. Chem. Mater. 25, 1592-1599 (2013).
} 
${ }^{22}$ Leclerc, H. et al. Infrared study of the influence of reducible iron(III) metal sites on the adsorption of $\mathrm{CO}, \mathrm{CO}_{2}$, propane, propene and propyne in the mesoporous metal-organic framework MIL-100. Phys. Chem. Chem. Phys. 13, 11748-11756 (2011).

${ }^{23}$ Eubank, J.F. et al. Porous, rigid metal(III)-carboxylate metal-organic frameworks for the delivery of nitric oxide. APL Mater. 2, 124112 (2014).

${ }^{24}$ Kwak, J.H. et al. Common intermediate for $\mathrm{N}_{2}$ formation in enzymes and zeolites: Side-on Cu-nitrosyl complexes. Angew. Chem., Int. Ed. 52, 9985-9989 (2013).

${ }^{25}$ Xiao, D.J. et al. Oxidation of ethane to ethanol by $\mathrm{N}_{2} \mathrm{O}$ in a metal-organic framework with coordinatively unsaturated iron(II) sites. Nature Chem. 6, 590-595 (2014).

${ }^{26}$ Seo, Y.-K et al. Large scale fluorine-free synthesis of hierarchically porous iron(III) trimesate MIL-100(Fe) with a zeolite MTN topology. Micropor. Mesopor. Mater. 157, 137-145 (2012).

${ }^{27}$ Gaab, M., Trukhan, N., Maurer, S., Gummaraju, R., Muller, U. The progression of Al-based metal-organic frameworks - From academic research to industrial production and applications. Micropor. Mesopor. Mater. 157, 131-136 (2012).

${ }^{28}$ Horcajada, P. et al. Porous metal-organic-framework nanoscale carriers as a potential platform for drug delivery and imaging. Nature Mater. 9, 172-178 (2010).

${ }^{29}$ Gascon, J., Corma, A., Kapteijn, F., Llabrés i Xamena, F.X. Metal Organic Framework Catalysis: Quo vadis? ACS Catal. 4, 361-378 (2014). 


\section{Methods}

Material synthesis. MIL-100(Fe), MIL-127(Fe), MIL-102(Fe) and MIL-53(Fe) were hydro/solvothermally prepared as described elsewhere ${ }^{18,30,31}$ (see SI for further details).

In situ IR characterization of MIL-100(Fe). Self supported samples were analysed in a quartz cell, using adapted probe molecules (see SI for further details and reference ${ }^{32}$ ).

Operando IR investigation of MIL-100(Fe). The IR operando system used for this study is constituted by a custom-made flow setup, a specifically developed reactor-cell and a set of gas analysers, as specified in SI and reference ${ }^{19}$. It allows a thorough time-resolved analysis of solid-gas heterogeneous catalytic reactions. In particular, the possibility to follow the IR surface spectra versus time, in parallel with the gas composition (sharing gas analysis via the simultaneous use of an IR gas analyser, a chemiluminescence and a mass spectrometer) allows investigating the reaction pathway from a qualitative and quantitative point of view. The sample was firstly activated at $523 \mathrm{~K}$ or $423 \mathrm{~K}$ (according to the purposes of the experiment, as discussed in the paper) under a flow of argon for 5 hours, to eliminate traces of impurities and adsorbed water. For the sake of clarity, we carefully excluded C-containing impurities such as $\mathrm{CO}_{2}, \mathrm{CO}$ and hydrocarbons in a feed mixture, even if habitually present in a combustion exhaust. Then a flow containing $1000 \mathrm{ppm} \mathrm{NO}, 10 \% \mathrm{O}_{2}, 1 \% \mathrm{H}_{2} \mathrm{O}$ in $\mathrm{Ar}$ as the vector gas was introduced into the cell heated at about $300 \mathrm{~K}$ (space hourly velocity varying between 5000 and $80000 \mathrm{~h}^{-1}$ ).

MIL-100(Fe) cluster model DFT calculations for NO binding. The cluster model calculations were carried out based on first principles density functional theory (DFT) calculations, implemented in $\mathrm{DMol}^{3}$ and Vienna Ab initio Simulation Package (VASP). More detailed procedures and results on the calculations are described in the SI.

\footnotetext{
${ }^{30}$ Serre, C. et al. Utilisation d'un solide hybride cristallin poreux comme catalyseur de réduction d'oxydes d'azote et dispositifs, 106660/FR patent filed 28/05/2009 ; PCT/ FR2010/000402 (28/05/2010)

${ }^{31}$ Horcajada, P. et al. J. Am. Chem. Soc. 130, 6774-6780 (2008).

${ }^{32}$ Vimont, A., Thibault-Starzyk, F., Daturi, M. Analysing and understanding the active site by IR spectroscopy, Chem. Soc. Rev. 39, 4928-4950 (2010).
} 
Acknowledgements The present paper is dedicated to the memory of Prof. Gérard Férey, who is among the pioneers of the MOFs synthesis and applications. He initiated us to this topic, always encouraging us to pursue new developments. We thank KRICT for its financial support (Grant No. KK-1401-F0) to part of this work. The Korean authors are grateful to the Global Frontier Center for Hybrid Interface Materials (GFHIM) for its financial support (Grant No. NRF-2013M3A6B1078879). We thank G. Maurin for critical discussions and reading of the manuscript.

Author Contributions M.D. designed the study, analysed data and wrote the paper. V.B.-A. and J.W.Y. collected data and treated them. P.B. supervised the operando investigation and adapted the system to the study specificities. A.V. performed the in situ investigation. J.-S.C. equally contributed to the design of this work and to the paper writing. Y.K.H. and Y.-K.S. performed the synthesis of materials and their characterisation. S.J and H.C. performed molecular simulation. C.S. contributed to the study and the paper writing. P.H. performed the synthesis of the materials and their characterisation. S.W. also participated to characterisations. All authors discussed the results and commented on the manuscript.

\section{Supplementary Information}

\section{Structure and synthesis of MOF solids MIL-100(Fe)}

MIL-100(Fe) is a trivalent metal carboxylate MOF with the chemical composition $\mathrm{Fe}_{3} \mathrm{O}\left(\mathrm{H}_{2} \mathrm{O}\right)_{2} \mathrm{~F}_{0.81}(\mathrm{OH})_{0.19} \cdot\left(\mathrm{C}_{6} \mathrm{H}_{5}\left(\mathrm{CO}_{2}\right)_{3}\right)_{2} \cdot \mathrm{nH}_{2} \mathrm{O}(\mathrm{n} \sim 14.5)$. As illustrated in Fig. 1 and Extended Data Figs. 2 and 3, MIL-100(Fe) consists of iron trimers (the secondary building unit) and 1,3,5-benzene tricarboxylic (the organic linker), which construct the so-called supertetrahedra ${ }^{18}$. The resulting structure exhibits several interesting features: a mesoporous zeotype architecture (Extended Data Fig. 2c) with a MTN (MTN = zeolite socony mobilthirty-nine) topology ${ }^{33}$, a huge unit cell volume $\left(\mathrm{V}_{\text {u.c. }}=388000 \AA^{3}\right)$, two mesoporous cages (cage diameters: 25 and $29 \AA$ - highlighted in Extended Data Fig. $2 c$ as green $(25 \AA)$ and red (29 $\AA$ ) cages - that are accessible through micropourous windows ( 5 and $9 \AA$ ), a high porosity (BET surface area $>2000 \mathrm{~m}^{2} \mathrm{~g}^{-1}$ and pore volume $\sim 1.2 \mathrm{~cm}^{3} \cdot \mathrm{g}^{-1}$ ) and a temperature stability under high vacuum until $523 \mathrm{~K}^{18}$. Moreover, it was already demonstrated for MIL-100(Cr) and MIL-100(Fe) by using in situ IR spectroscopy, that each metal octahedron possesses one terminal group, where $\mathrm{H}_{2} \mathrm{O}, \mathrm{OH}^{-}$or $\mathrm{F}^{-}$is adsorbed after the synthesis and it can transform in a undercoordinated site after temperature activation ${ }^{22,34}$. In the case of MIL-100(Fe), there is the possibility of the generation of iron CUS with mixed valence $\mathrm{Fe}^{\mathrm{II}} / \mathrm{Fe}^{\mathrm{III}}$ by temperature treatment ${ }^{35}$. Despite the creation of $\mathrm{Fe}^{\mathrm{II}}$ and $\mathrm{Fe}^{\mathrm{III}} \mathrm{CUS}$, the overall structure of MIL-100(Fe) does not change ${ }^{19,35}$. 
MIL-100(Fe) was hydrothermally synthesized in presence of $\mathrm{HF}$ as previously reported ${ }^{18}$. Activation of MIL-100(Fe) consisted in the suspension of $2.5 \mathrm{~g}$ of the as-synthesized solid in $350 \mathrm{~mL}$ of water at $70^{\circ} \mathrm{C}$ for $3 \mathrm{~h}$ and then in $200 \mathrm{~mL}$ ethanol at $60^{\circ} \mathrm{C}$ for $3 \mathrm{~h}$. Further activation was carried out by redispersing the solid in $100 \mathrm{~mL}$ of a $38 \mathrm{mM}$ aqueous $\mathrm{NH}_{4} \mathrm{~F}$ solution at $70^{\circ} \mathrm{C}$ for $3 \mathrm{~h}$, subsequently recovering the solid by filtration and repeating a water washing ( $350 \mathrm{~mL}$ at room temperature for $3 \mathrm{~h}$ ) to remove the remaining $\mathrm{NH}_{4} \mathrm{~F}$.

\section{MIL-127(Fe) of $\operatorname{Soc}-\mathrm{MOF}(\mathrm{Fe})$}

MIL-127(Fe), isostructural to soc-MOF(In) reported by Eddaoudi et al. ${ }^{36}$, is built from iron(III) octahedra trimers linked by the 3,3',5,5'-azobenwenetetracarboxylic acid linkers, leading to the chemical formula $\mathrm{Fe}_{3} \mathrm{OF}\left(\mathrm{H}_{2} \mathrm{O}\right)_{3}\left(\mathrm{C}_{16} \mathrm{~N}_{2} \mathrm{O}_{8} \mathrm{H}_{6}\right)_{1.5} . n \mathrm{H}_{2} \mathrm{O}$. Each trimer unit is linked by six separate ditopic organic linkers to build up a $3 \mathrm{D}$ cubic structure. In each octahedron, the apical position is occupied by a terminal water molecule. Each trimer unit is linked by six separate organic linkers to produce a cubic 3D structure with the soc topology (Extended Data Fig. 3b). ${ }^{37}$ Each iron atom is trivalent, yielding an overall cationic framework $(+1$ per formula unit) that is balanced here by fluorine ions. This solid exhibits an important porosity $\left(\mathrm{S}_{\mathrm{BET}} \sim\right.$ $\left.1400 \mathrm{~m}^{2} \cdot \mathrm{g}^{-1}, \mathrm{~V}_{\mathrm{p}} \sim 0.7 \mathrm{~cm}^{3} \cdot \mathrm{g}^{-1}\right)$ with two types of pores: i) an accessible 1D channels system ( 5-7 $\AA$ ), and cages of $\sim 10 \AA$ accessible through windows of $\sim 3 \AA$, allowing only the adsorption of small molecules such as $\mathrm{H}_{2} \mathrm{O}$ or $\mathrm{H}_{2}$.

MIL-127(Fe) was solvothermally synthesized as previously reported ${ }^{38}$. The resulting product was filtered, washed with dimethylformamide and then heated at $200^{\circ} \mathrm{C}$ under primary vacuum for $15 \mathrm{~h}$.

\section{MIL-102(Fe)}

MIL-102 is also a trivalent metal carboxylate MOF based on iron(III) octahedra trimers connected, in this case, by 1,4,5,8-naphthalentetracarboxylate, leading to the chemical formula $\mathrm{Fe}_{3} \mathrm{O}(\mathrm{OH})\left(\mathrm{H}_{2} \mathrm{O}\right)_{2}\left[\mathrm{C}_{10} \mathrm{H}_{2}-\left(\mathrm{CO}_{2}\right)_{4}\right]_{1.5} \cdot n \mathrm{H}_{2} \mathrm{O}$.

Iron(III) octahedra trimers link through the naphthalentetracarboxylate anions, creating a hexagonal three-dimensional framework $\left(\mathrm{V}_{\text {u.c. }} \sim 1330 \AA^{3}\right.$; Extended Data Fig. 3c). Each iron atom exhibits an corner-sharing octahedrally coordinated environment with four oxygen atoms from the bidentate carboxylates, one $i 3$-oxo atom, and one terminal site. The latter site can be occupied by a terminal water molecule and/or an anion (typically - $\mathrm{OH}$ ), leading to the formation of a trimeric iron subunit. Along [001], each trimer is connected to its equivalent by the bridging carboxylate functions of the organic moiety. A special kind of nanotube which shares the central C-C bond of the naphthalene groups is formed. The hexagonal arrangement of such nanotubes creates 1D pore channels of $\sim 3-4 \AA$ along the $c$-axis, where six free water molecules are located. Terminal water molecules or hydroxy anions point toward the center of the tunnels.

MIL-102(Fe) was hydrothermally synthesized as previously reported ${ }^{30}$. The resulting product was purified by suspending $2.5 \mathrm{~g}$ of the as-synthesized solid in $350 \mathrm{~mL}$ of ethanol at room temperature for $3 \mathrm{~h}$. This procedure was repeated until the complete removal of the free ligand, as confirmed by IR. 


\section{MIL-53(Fe)}

MIL-53(Fe) is built up from chains of trans corner-sharing of iron(III) octahedra (Extended Data Fig. 3d) joined together in the two other directions via terephthalate anions ${ }^{39}$, creating a three-dimensional structure with a diamond-shape microporous 1D pore system (Extended Data Fig. 3d). MIL-53 exhibits a flexible structure ${ }^{40,41,42}$, able to reversibly adapt its pore size in presence of different stimuli (temperature, guest adsorption, pressure), from a close form $\left(\mathrm{V}_{\text {u.c. }} \sim 900-1000 \AA^{3} \varnothing \sim 4 \AA\right.$ ) $)$ to an open form $\left(\mathrm{V}_{\text {u.c. }} \sim 1400-500 \AA^{3} ; \varnothing \sim 8.5 \AA\right.$ ) with a variation of their cell volume (up to $40 \%$ ) without any bond breaking. ${ }^{43}$

MIL-53(Fe) was solvothermally synthesized as previously reported ${ }^{30}$. The resulting product was purified by suspending $2.5 \mathrm{~g}$ of the as-synthesized solid in $350 \mathrm{~mL}$ of ethanol at room temperature for $3 \mathrm{~h}$. This procedure was repeated until the complete removal of the free ligand, as confirmed by IR.

\section{DFT calculations}

To analyse the consequences of the oxidation state of the iron sites over the NO binding, cluster model calculations of MIL-100(Fe) based on first principles density functional theory (DFT) calculations, were first carried out.

Firstly, we construct a cluster model including a symmetric Fe trimer from the reported MIL100(Fe) structure ${ }^{18}$, as shown in Extended Data Fig. 4(a). This large cluster for hydrated model consists of $\mathrm{Fe}_{3} \mathrm{O}(\mathrm{F})\left(\mathrm{H}_{2} \mathrm{O}\right)_{2}\left[\left(\mathrm{C}_{6} \mathrm{H}_{3}\right)\left(\mathrm{CO}_{2}\right)(\mathrm{Me})_{2}\right]_{6}$ units, where two ending $\left(\mathrm{CO}_{2}\right)$ 's of trimesate are replaced by methyl group (Me)s. Then the atomic structure of the large cluster was optimized to give the lowest total energy as keeping trimesate structure using Dmol ${ }^{3}$ $\operatorname{code}^{44,45}$. For hydrated large cluster calculations, we can confirm two different Fe oxidation states, $\mathrm{Fe}$ (III) facing $\mathrm{H}_{2} \mathrm{O}$ and $\mathrm{Fe}(\mathrm{II})$ facing $\mathrm{F}$ from the molecular orbital analysis. In order to investigate the electronic structures of $\mathrm{Fe}$ in a more detailed manner, we built a smaller cluster including "one" Fe atom with F, as shown in Extended Data Fig. 4(b), from the optimized atomic structure of the large cluster. This small cluster consists of $(\mathrm{FeO})(\mathrm{F})\left(\left(\mathrm{CO}_{2}\right) \mathrm{Me}\right)_{4} \mathrm{C}_{2}$ units, where $\left[\left(\mathrm{C}_{6} \mathrm{H}_{3}\right)\left(\mathrm{CO}_{2}\right)_{3}\right]$ was replaced by $\left(\left(\mathrm{CO}_{2}\right) \mathrm{Me}\right)$ and the other two $\mathrm{Fe}$ atoms of the $\mathrm{Fe}$ trimer were replaced by carbon atoms keeping the atomic and electronic structure of the large cluster. For the small Fe cluster calculations, we used the Vienna Ab initio Simulation Package (VASP) ${ }^{46}$. Starting from a fluorinated small cluster, Fe(II) was obtained by removing $\mathrm{F}$ atom, whereas $\mathrm{Fe}(\mathrm{III})$ was obtained by removing $\mathrm{F}^{-}$ion. We found that the high spin states of $\mathrm{Fe}$ (II) and $\mathrm{Fe}$ (III) have the lowest total energies, as spin quintet ( $\mathrm{S}=4$ ) and spin sextet $(S=5)$, respectively. For the investigation of the NO binding characters, the binding energies and charge transfer amount of $\mathrm{NO}$ molecule to $\mathrm{Fe}$ (II) and $\mathrm{Fe}$ (III) were calculated, as listed in the table Extended Data Fig. 4(c). NO molecule binds to Fe ions with an angle of about $120-140^{\circ}$. NO molecule is more strongly bound to $\mathrm{Fe}(\mathrm{II})$ than $\mathrm{Fe}$ (III) with an higher binding energy and a shorter distance. The Bader charge ${ }^{47}$ values were used to calculate the charge transfer of the NO molecule. The charge transfer of NO to $\mathrm{Fe}(\mathrm{II})$ is bigger than to $\mathrm{Fe}(\mathrm{III})$, and the electron transfer directions are opposite. NO molecule tends to attract electrons from $\mathrm{Fe}(\mathrm{II})$, whereas it tends to lose electrons to $\mathrm{Fe}(\mathrm{III})$. When NO molecule is bound to $\mathrm{Fe}(\mathrm{II})$ strongly, the distance between $\mathrm{N}$ and $\mathrm{O}$ is getting longer than its molecular distance for the free molecule, therefore NO intramolecular bonding could be weakened when the species is bound to $\mathrm{Fe}(\mathrm{II})$. That can explain why $\mathrm{Fe}(\mathrm{II})$ sites are more active in NO 
dissociation.

In our DFT cluster calculations, we used two different DFT codes, Dmol ${ }^{3}$ and VASP codes. $\mathrm{DMol}^{3}$ was used to determine the atomic structures and oxidation states of Fe ions with the big cluster model. VASP code was used for NO binding state with small cluster models, for more accurate description of spin states of Fe, since VASP is known to give a good agreement with experiments for magnetism of $\mathrm{Fe}$ ion. In both calculations, the spin-unrestricted DFT cluster calculations were carried out with the Perdew-Burke-Ernzerhof (PBE) functional. For $\mathrm{Dmol}^{3}$ calculations, the numerical basis set of DNP and DFT semicore pseudopotentials (DSPPs) for $\mathrm{Fe}$ were employed and van der Waals interactions are included within Tkatchenko-Scheffler $(\mathrm{TS})^{48}$ scheme, as implanted in Dmol ${ }^{3}$. In the VASP code, periodic plane-wave basis sets are used with frozen-core projector augmented wave (PWA) pseudopotentials $^{49}$. For $\mathrm{Fe}$ atoms, GGA+U was employed with $\mathrm{U}=2.5 \mathrm{eV}$. In VASP calculations, van der Waals interactions are also included with Grimme scheme ${ }^{50}$.

\section{Reaction tests in a catalytic reactor}

A sample of MIL-100 (Fe) of about $1.5 \mathrm{~g}$ was put in a tubular reactor connected to a system for introduction and analysis of gas phases (by gas chromatography and mass spectrometry). The sample was pretreated by passing a helium stream $(100 \mathrm{~mL} / \mathrm{min})$ over it for $6 \mathrm{~h}$ at $250^{\circ} \mathrm{C}$. The experiment was then conducted at $30^{\circ} \mathrm{C}$, under a mixture of $1000 \mathrm{ppm}$ of $\mathrm{NO}$ and $\mathrm{He}$ as carrier gas, adding or not $10 \%$ of oxygen and $1 \%$ of water. The total flow was set to obtain a space velocity of $15000 \mathrm{~h}^{-1}$.

When NO only is sent to the reactor, only absorption phenomena are observed. In the presence of oxygen and absence of water, $82 \%$ of $\mathrm{NO}$ is converted into $\mathrm{NO}_{2}$ after contact with MIL-100(Fe) powder. Feeding the reactor with the full gas mixture $\left(\mathrm{NO}+\mathrm{O}_{2}+\mathrm{H}_{2} \mathrm{O}\right.$ in $\left.\mathrm{He}\right)$ provides a steady conversion of NOx into $\mathrm{N}_{2}$, reaching an efficiency of $34 \%$.

\section{In situ IR characterization}

Samples were pressed $\left(\sim 10^{2} \mathrm{MPa}\right)$ into self-supported disks $\left(2 \mathrm{~cm}^{2}\right.$ area, $\left.7-10 \mathrm{mg} \mathrm{cm}{ }^{-2}\right)$ and placed in a quartz cell equipped with $\mathrm{KBr}$ windows. A movable quartz sample holder permits one to adjust the pellet in the infrared beam for spectra recording and to displace it into a furnace at the top of the cell for thermal treatment. The cell was connected to a vacuum line for evacuation $\left(\mathrm{P}_{\text {residual }} \cong 10^{-4} \mathrm{~Pa}\right)$ and for the introduction of gases into the infrared cell. Spectra were recorded at room temperature, except in the case of $\mathrm{CO}$ adsorption experiment where the pellet was maintained at $100 \mathrm{~K}$ by cooling the sample holder with liquid nitrogen after quenching the sample from the thermal treatment. The addition of well known doses of gases in the cell was possible via a calibrated volume connected to a pressure gauge for the control of the gas pressure. A Nicolet Nexus spectrometer equipped with a Mercury Cadmium Telluride (MCT) cryodetector and an extended $\mathrm{KBr}$ beam splitter was used for the acquisition of spectra recorded at room temperature in the $600-5500 \mathrm{~cm}^{-1}$ range. IR spectra are absorbance spectra and the notation used is a.u. for absorbance units. The resolution of the spectra was $4 \mathrm{~cm}^{-1}$, and 256 scans were accumulated for each spectrum. A self-supported MIL-100(Fe) solid strongly absorbs the IR light between 1300 and $1650 \mathrm{~cm}^{-1}$ (region of the carboxylates stretching vibrations). 


\section{Operando IR characterisation}

The IR operando system, which was used for this study, is composed of four main parts: the infrared spectrometer, the IR reactor-cell, the gas flow set-up and the exhaust gas analysers. The cell was connected to the operando gas-system including mass flow controllers for the introduction of gases into the lines. Two gas mixtures can be prepared and sent independently to the reactor cell. The system allows investigating the exhaust gases (reactive and/or reaction products) simultaneously by a Quadrupole Mass Spectrometer (Pfeiffer Omnistar GSD 301), an IR gas micro-cell of $0.088 \mathrm{~cm}^{3}$ volume and a Thermo Electron model 10A rack-mounted Chemiluminescent NO-NOx gas analyser at the same time. This is a very important option to follow qualitatively and quantitatively the molecular composition of the gas: some of the molecules can be measured only by a single instrument, while the molecules detected by multiple analysers permit to verify the coherence among the experimental data. IR spectra (64 scans per spectrum) are collected with a Thermo Scientific Nicolet 6700 spectrometer, equipped with a MCT detector. More details can be found in the following references ${ }^{51-53}$. The IR reactor-cell used in this study is a so-called "Sandwich" operando cell developed by the LCS scientists and engineers, and described in details elsewhere ${ }^{19}$. This apparatus works in the domain of temperature $298-873 \mathrm{~K}$. The sample is placed in the toroidal sample holder (in the centre of the cylindrical body) in the form of a self-supported wafer of $8-9 \mathrm{mg} \mathrm{cm}^{-2}$. The required tightness of the cell can be obtained by using Kalrez O-rings between the terminal $\mathrm{KBr}$ windows and the extremities of the cell. The rest of the space is filled by $\mathrm{KBr}$ windows, which limit the reactor volume to $0.42 \mathrm{~cm}^{3}$. The experiment was carried out at atmospheric pressure; gases are introduced onto the sample by a $1 / 8$ " OD pipe and collected on the opposite side of the sample holder.

\section{Detailed analysis of the time-resolved gas composition and infrared spectra of the sample}

The DeNOx reaction has been tested several times, both in the operando setup and in a classical plug flow reactor, to ensure a correct repeatability ${ }^{30}$. Note that a casted wafer presents a lower catalytic efficiency respect to the corresponding powder, as pointed out $\mathrm{in}^{54}$. Nevertheless, it provides spectroscopic evidences useful for the comprehension of the chemical process. Leaving the catalyst under stream up to 3 days does not change the NO conversion, nor the nitrogen yield, within the experimental error, as shown in Extended Data Fig. 5, for example. This is a very important point, since it demonstrates the catalytic nature of the reaction. In fact, the experimental data show that a stable conversion of NOx is obtained over more than $3000 \mathrm{~min}$. Therefore, if the conversion is of at least $13 \%$ in a gas flow $(25 \mathrm{~mL} / \mathrm{min}$ ) containing $1000 \mathrm{ppm} \mathrm{NO}$, i.e. corresponding to a NOx conversion above $130 \mathrm{ppm}$ over the entire period, more than $1350 \mu \mathrm{mol}$ of NOx are converted per gram of catalyst, well above the maximum amount of $850 \mu \mathrm{mol} / \mathrm{g}$ of $\mathrm{Fe}^{2+}$ sites measured after reducing MIL-100(Fe $)^{22}$. This rule out the possibility of a molecular reaction. Thus, when the gas feed is in contact with the sample activated at $523 \mathrm{~K}$ under Ar, a catalytic transformation of NO into dinitrogen can be observed (Figure 2d), concurrently with the formation of $\mathrm{Fe}^{\mathrm{II}}$ dinitrosyls (Figure 2b). This conversion (for a casted sample: 13\% at the gas hourly space velocity, GHSV $=5000 \mathrm{~h}^{-1} ; 8 \%$ for a GHSV of $15,000 \mathrm{~h}^{-1} ; 4.5 \%$ for a GHSV $=80,000 \mathrm{~h}^{-1}$ ) is selective, as evidenced by both the signal $\mathrm{m} / \mathrm{z}=28$ in mass spectrometry and the absence of 
any other detectable $\mathrm{N}$-containing species, such as $\mathrm{N}_{2} \mathrm{O}$ or ammonia, easily detectable by IR. On the contrary, if the sample is activated, for example, at $423 \mathrm{~K}$ no Fe ${ }^{\mathrm{II}}$ sites are detectable on the surface via the adsorption of probe molecules and no reactivity can be observed (Extended Data Figure 1), except for a partial $\mathrm{NO}$ to $\mathrm{NO}_{2}$ oxidation. If the same sample is further activated at higher temperature, $\mathrm{Fe}^{2+}$ species are clearly seen and the NO dissociation activity starts, as previously shown in Figure 2. Therefore the catalytic activity is linked to the presence of $\mathrm{Fe}^{2+}$ sites, promoted by the treatment at higher temperature.

Also, the catalytic reaction takes place only when oxygen and water are co-added to NO in the gas flow, as shown in Figure 3. The presence of NO alone doesn't promote any catalytic reaction (Fig. 3a, S1). The addition of oxygen provokes a consistent oxidation of $\mathrm{NO}$ to $\mathrm{NO}_{2}$ (about $45 \%$, Fig. 3a, S2), whereas only the successive introduction of water in the gas flow promotes the catalytic activity for NOx elimination (Fig. 3b, S3).

Considering now the concomitant IR spectra of the material, we observe that sending a flow containing $1000 \mathrm{ppm} \mathrm{NO}, 10 \% \mathrm{O}_{2}, 1 \% \mathrm{H}_{2} \mathrm{O}$ in $\mathrm{Ar}$ as the vector gas on the sample at about $300 \mathrm{~K}$ provokes, first, the formation of NO adsorbed species on iron sites, as witnessed by the doublet at 1841 and $1827 \mathrm{~cm}^{-1}$, typical for nitrosyls on Fe ${ }^{\text {II }} 19$ (Figure 2b).

After time on stream, while the nitrosyls decrease other bands appear in the region 2300-1600 $\mathrm{cm}^{-1}$. The band at $1879 \mathrm{~cm}^{-1}$ can be associated with the $v(\mathrm{~N}=\mathrm{O})$ stretches of adsorbed $\mathrm{N}_{2} \mathrm{O}_{3}$ species, being the $v_{\mathrm{as}}(\mathrm{NO})_{2}$ mode hidden by the carboxylate massif and the $v_{\mathrm{s}}(\mathrm{NO})_{2}$ mode contained in the small massif centered at $1285 \mathrm{~cm}^{-1}$ (Extended Data Figure 6) ${ }^{55}$. The band at $1773 \mathrm{~cm}^{-1}$ can be assigned to the $v(-\mathrm{O}=\mathrm{N})$ vibration of the antisymmetric NONO, which is produced at a low temperature in the presence of Lewis acid sitesErreur ! Signet non défini.. The alternative to assign the features at 1879 and $1773 \mathrm{~cm}^{-1}$ to dinitrosyls, probably bent ${ }^{55}$, would be inaccurate: (i) if the 1879 and $1773 \mathrm{~cm}^{-1}$ bands are assigned to the same species, they should have the same kinetics, which is not the case (see Figure $2 b$ \& c); (ii) it is quite unlikely that dinitrosyls appear when the consumption of mononitrosyls by reaction becomes evident. The bands at 1715 and $1733 \mathrm{~cm}^{-1}$ are likely due to adsorbed $\mathrm{NO}_{2}$ or $\mathrm{N}_{2} \mathrm{O}_{4}$ (presenting also a band at $2185 \mathrm{~cm}^{-1}$ ). Since $\mathrm{NO}$ and $\mathrm{O}_{2}$ were fed in the gas mixture, we can conclude that oxidation of $\mathrm{NO}$ into $\mathrm{NO}_{2}$ has taken place on the surface as confirmed by the analysis of the exhaust gas in Fig. 2d and 3. The described evidence is not an obvious result. In fact, some of metal oxides (such as $\mathrm{Mn}$ and Ce-based oxides ${ }^{56}$ ) are known to catalyze the oxidation reaction of $\mathrm{NO}$ into $\mathrm{NO}_{2}$. However, this phenomenon has never been observed on a MOF, or on iron oxide to the best of our knowledge, but only on iron porphyrins ${ }^{57}$. Additionally, the oxidation is also effective in the presence of only $\mathrm{Fe}^{\mathrm{III}}$ sites in MIL-100(Fe), as observed in Extended Data Fig. 1.

Considering the additional bands present at lower wavenumbers (Fig. 2b and Extended Data Fig. 6), we can tentatively assign the doublets at $1696-1683$ and $1133-1123 \mathrm{~cm}^{-1}$ to nitrates, while the bands at 1285 and $1238 \mathrm{~cm}^{-1}$ are compatible with the presence of nitrites ${ }^{55,58}$, even if the intense modes of carboxylates impeach band resolution in this region of the spectra. Interestingly, when these nitrogen-containing species are formed $\mathrm{NO}^{+}$moieties are concomitantly detected, as indicated by a band at $2188 \mathrm{~cm}^{-1}$ (Extended Data Fig. 7), similar to that formed on zeolites in similar conditions and considered as an intermediate for NOx 


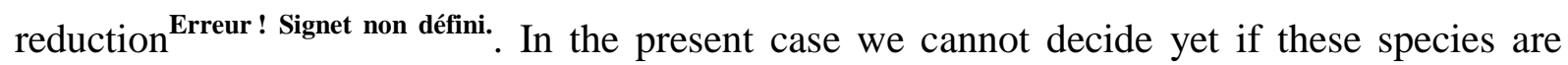
relevant for the reaction mechanism or if they are barely spectators.

Scrutinizing the spectra in the Extended Data Figure 7, we also remark that nitrosyls on $\mathrm{Fe}^{3+}$ appear since the first contacts between the surface and the gas phase (bottom spectra), giving rise to a band at $1901 \mathrm{~cm}^{-1}$, much weaker than the corresponding species on $\mathrm{Fe}^{2+}$, as already remarked $^{22,34}$. This band follows the trend of those for the other nitrosyls, i.e. increasing, then decreasing, until to be undetectable, due to the overlapping with the overtones of structural bands in the 1950-1870 $\mathrm{cm}^{-1}$ region, perturbed by the formation of adsorbed phases. Similarly, the features of bands between 2150 and $1950 \mathrm{~cm}^{-1}$ are difficult to interpret; looking at the direct spectra (Extended Data Figure 8), they seem to be due to changes in the background spectra, enhanced by the difference between each spectrum and the reference. We can mention that Busca and Lorenzelli reported the presence of $\mathrm{NO}_{2}{ }^{-}$in this region ${ }^{59}$, which is not unlikely.

In the $\mathrm{OH}$ stretching region we observe the formation of sharp bands at 3680 and $3604 \mathrm{~cm}^{-1}$ assigned to molecular water coordinatively adsorbed on $\mathrm{Fe}^{3+} \mathrm{CUS}$, and a broad massif around $3100 \mathrm{~cm}^{-1}$ due to $\mathrm{H}$-bonded water species ${ }^{22}$. The pristine $\mathrm{Fe}^{\mathrm{II}}$ hydroxyls ${ }^{60}$ at $\sim 3621 \mathrm{~cm}^{-1}$ progressively disappear during the chemical reaction, in parallel with nitrosyls on $\mathrm{Fe}^{2+}$. Additional bands are formed at 3700 and $3674 \mathrm{~cm}^{-1}$. Are these features related with the NO reduction mechanism? It is likely the case, considering that (as mentioned above) the presence of water is necessary to observe the catalytic reaction although their role is still unclear.

To better understand the phenomena taking place on the surface of MIL-100(Fe) and correlate them with the species observed in the gas phase, it is worth considering the kinetic behaviour of each entity. Fig. 2c shows the intensity profiles of the aforementioned species versus reaction time at the initial stage of the reaction. The time sequence for $\mathrm{N}$-containing species appearing and disappearing is quite clear. Nitrosyl species are first formed on $\mathrm{Fe}^{\mathrm{II}}$ sites, until their intensities reach a maximum, and then decrease. $\mathrm{NO}_{2}$ is also formed first on the surface of the sample, and then detected in the gas phase. The proximity between coordinated NO and $\mathrm{NO}_{2}$ gives rise to $\mathrm{N}_{2} \mathrm{O}_{3}$ moieties, to nitrates (nitrites) and $\mathrm{NO}^{+}$species, while hydroxyls are perturbed and consumed (being partially restored by water in the vapour phase). This is normally proposed to happen through HNOx intermediates, which cannot be revealed here due to the vibrational modes of carboxylates superimposed to their typical bands ${ }^{\text {Erreur } \text { : Signet }}$ non défini. Therefore, we can imagine that hydroxyls may have a role in the formation of these HNOx intermediates, if any.

\section{Tentative reaction scheme for NO reduction at room temperature}

Considering the spectroscopic evidences and all the elements provided in the abovementioned discussion, we can hypothesise a global reaction mechanism, as represented in Extended Data Figure 9: (i) NO is first adsorbed on neighbouring Fe(II) and Fe(III) sites; (ii) on the latter it is oxidized to $\mathrm{NO}_{2}$, with the concomitant reduction of the adsorption iron site; (iii) $\mathrm{N}_{2} \mathrm{O}_{3}$ is formed, but in the presence of water (coordinated or split as $\mathrm{OH}$ groups) it is destabilised (iv), forming nitrogen protoxide upon oxygen release. At this step (v), $\mathrm{N}_{2} \mathrm{O}$ decomposes yielding nitrogen and reoxidising the $\mathrm{Fe}$ (II) site to the original $\mathrm{Fe}$ (III) centre; (vi) after then, the sites are finally only occupied by hydroxyls and weakly adsorbed water, so ready for a new catalytic cycle. 
Obviously this description is speculative at this stage, but it is interesting to remark that the first three steps well matches with the spectroscopic evidences mentioned above, while the additional ones have already been evoked to explain the NO decomposition mechanism on $\mathrm{Cu}$-zeolites, and found to be favourable at low temperature ${ }^{61,62}$. The oxygen release mentioned in step (iv) cannot be evidenced experimentally for technical reasons and in the absence of isotopically labelled oxygen species. However, dedicated experiments have discarded the possibility that oxygen could be adsorbed molecularly and reoxidation phenomena were not evidenced at this step. Therefore, considering that the reaction is catalytic and that the yielded nitrogen matches with the mass balance in the NO conversion, oxygen can only be released.

Additionally, two evidences plead in favour of the reaction pathway scheme described above: i) the kinetics of the most relevant species presented in Fig. 2c presents the typical trend of a consecutive reaction: the primary reactant (NO) coordinates with the iron reaction sites, as visualised by the decreasing of the Fe-hydroxyls; iron nitrosyls are formed, they increase in intensity reaching a maximum, then decrease (as a typical intermediate) when $\mathrm{NO}_{2}$ and $\mathrm{N}_{2} \mathrm{O}_{3}$ are formed; at this moment the final product $\mathrm{N}_{2}$ is produced.

ii) Preliminary studies (not shown here for the sake of brevity) on similar non-redox MOFs as, for example, MIL-100(Cr)) show the above mentioned species on the surface, but $\mathrm{N}_{2} \mathrm{O}$ is yielded in spite of nitrogen.

Additionally, to verify a fundamental part of the mechanism and the central role of nitrogen oxide into nitrogen dioxide transformation, we have repeated the reaction feeding the catalyst with a mixture of $500 \mathrm{ppm} \mathrm{NO}+500 \mathrm{ppm} \mathrm{NO}$, instead of $1000 \mathrm{ppm} \mathrm{NO}$. If $\mathrm{NO}_{2}$ is an intermediate, its direct introduction should favour the reaction, skipping the potential limiting step. Effectively, as evidenced in Extended Data Figure 10, the efficiency rises from 8\% to $34 \%$ at GHSV $=15000 \mathrm{~h}^{-1}$. But further studies should be performed to ascertain this and other points.

\section{Reactivity tests on MIL-127(Fe), MIL-53(Fe) and MIL-102(Fe) samples}

MIL-127(Fe), MIL-53(Fe) and MIL-102(Fe) samples were submitted to the same catalytic tests as MIL-100(Fe), using the same gas composition, contact time and powder amount. Catalytic results showed a similar NO conversion for MIL-127(Fe) as that measured for MIL$100(\mathrm{Fe})$, within the experimental error. On the opposite, at the steady state, no nitrogen monoxide conversion was measured for the other two samples.

\section{Introduction of impurities in the reaction flow}

In the experimental conditions used to assess the MIL activity for NO decomposition we have skipped carbonic impurities in the feeding flow to keep the quantification on nitrogen yield unambiguous, without contributions to $\mathrm{m} / \mathrm{z}=28$ other than provided by $\mathrm{N}_{2}$. Successively, the effect on the reaction of gaseous species typically present in the combustion engine exhaust has been investigated. Obviously, the survey of all the impurities present in real exhaust is outside the purpose of the present report; we have considered only the gases present in the highest concentrations and currently analysed in deNOx studies.

We didn't expect a big effect of CO or hydrocarbons on NOx adsorption, because we already found that $\mathrm{NO}$ adsorption on $\mathrm{Fe}^{2+}$ site is stronger (see results in references 19 and 22). But we have preferred to verify adding $\mathrm{CO}$ in the reaction flow. Even, to better simulate the 
conditions offered by an automotive exhaust, we have mixed to the flow $\mathrm{CO}$ and $\mathrm{H}_{2}$ in a 3:1 ratio (as it results from gasoil combustion; see for example ${ }^{63}$ ). Up to a concentration of $6.4 \%$ $\mathrm{CO}$ and $2.13 \% \mathrm{H}_{2}$ (well above the currently measured concentrations) we haven't found any effect on the reaction.

In respect to sulfur compounds, MIL-100(Fe) has shown poor affinity ${ }^{64}$.

Concerning $\mathrm{CO}_{2}$, in a recent past we have performed deep investigations on $\mathrm{CO}_{2}$ capture and storage in different MOF families. Among them, MIL-100 was not the most efficient material for trapping carbon dioxide ${ }^{65}$. Moreover, considering that the sample can be totally regenerated by $\mathrm{CO}_{2}$ adsorption already at $303 \mathrm{~K}$ and that water competes with $\mathrm{CO}_{2}$ on the adsorption sites ${ }^{65}$, the influence of carbon dioxide on the NO adsorption and reaction cannot be relevant. However, considering the high concentrations of $\mathrm{CO}_{2}$ in all the combustion exhausts, this point needed verification. Therefore we have repeated the experiments in the presence of carbon dioxide and verified that $\mathrm{NO}$ always wins the competition with $\mathrm{CO}_{2}$ on the adsorption sites. Consequently, the reactivity was found unchanged in an appreciable way.

\section{Extended Data}
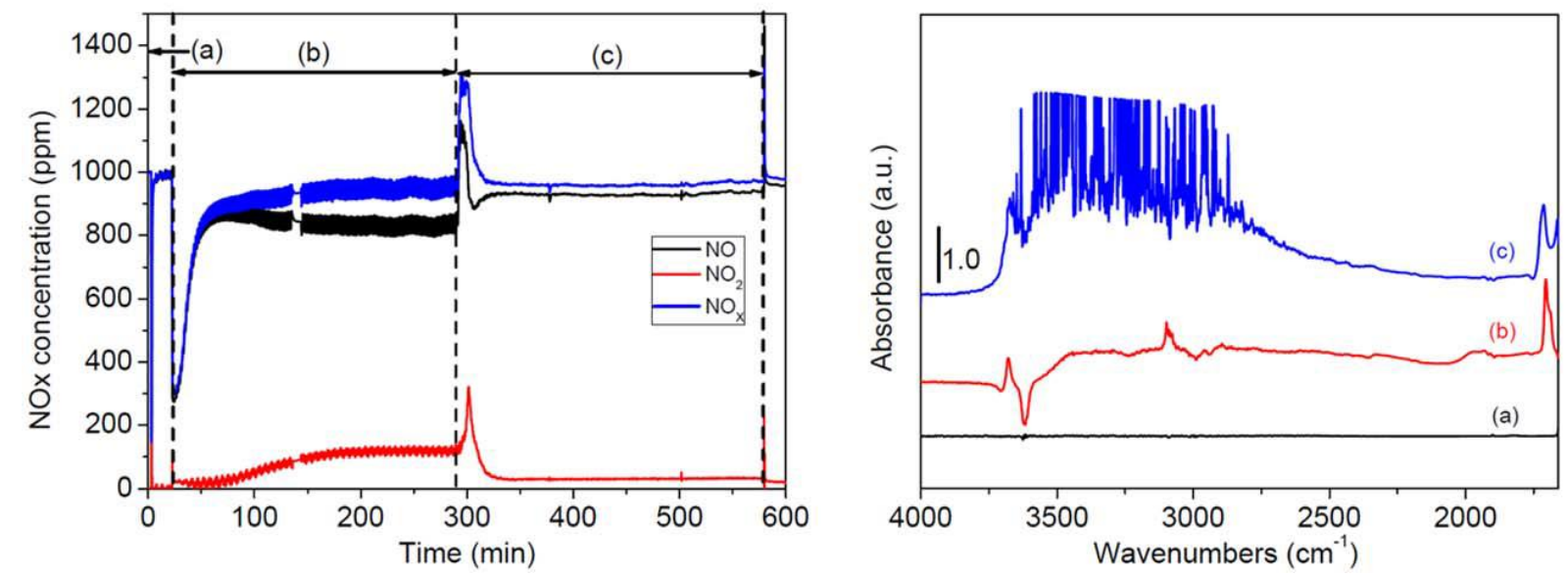

Extended Data Figure 1: effect of the activation temperature. Left: NOx concentrations (chemiluminescence profiles) after gas contact with the MIL-100(Fe) sample submitted to a flow of $1000 \mathrm{ppm} \mathrm{NO}(\mathrm{a})$, then adding $10 \% \mathrm{O}_{2}$ (b) and $1 \% \mathrm{H}_{2} \mathrm{O}(\mathrm{c})$, after activation at $423 \mathrm{~K}$. Data show that no deNOx reaction is detected (but $\mathrm{NO}$ to $\mathrm{NO}_{2}$ partial oxidation can be observed). Right: transmission FTIR spectra of the corresponding sample surface at the steady state, showing the absence of $\mathrm{Fe}^{\mathrm{II}}$ sites on the sample surface. 


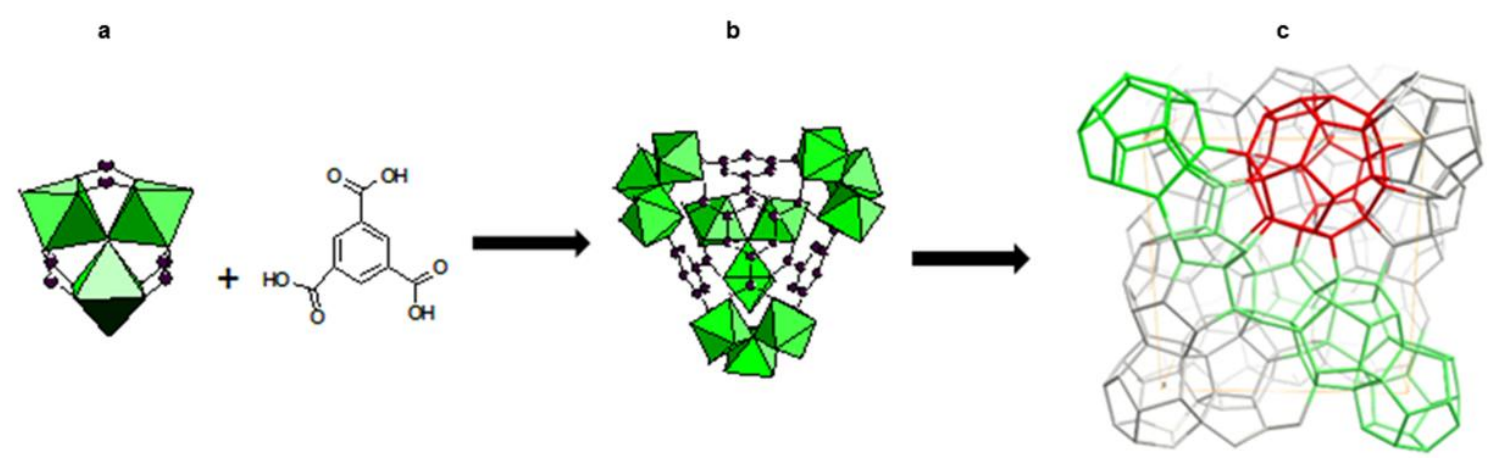

Extended Data Figure 2: Structure of MIL-100. a, the secondary building unit (trimer of chromium, octahedral) and the organic liker $(1,3,5-\mathrm{BTC}=$ benzene tricarboxylic or trimesic acid); b, the hybrid supertetrahedron; c, unit cell of MIL-100 with a schematic view of the MTN topology (Figure published in reference19).
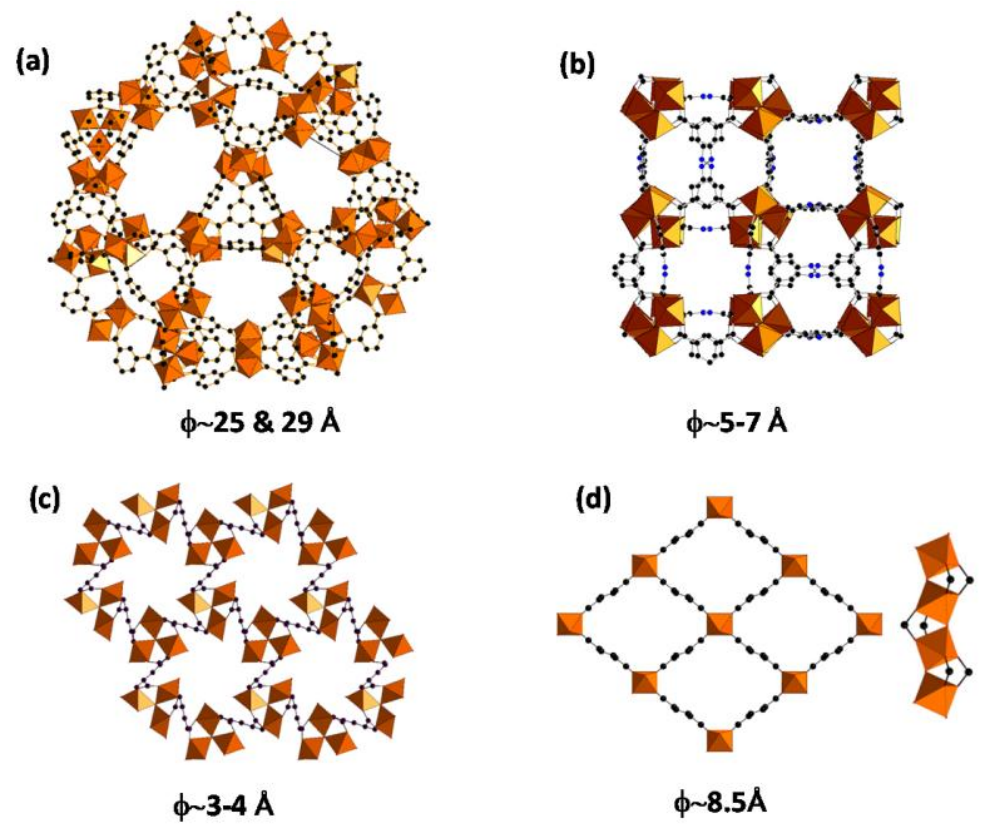

Extended Data Figure 3: Schematic representation of the structure of MIL-100(Fe) (a), MIL-127(Fe) (b), MIL-102(Fe) (c) and MIL-53(Fe) (d) solids. 
a

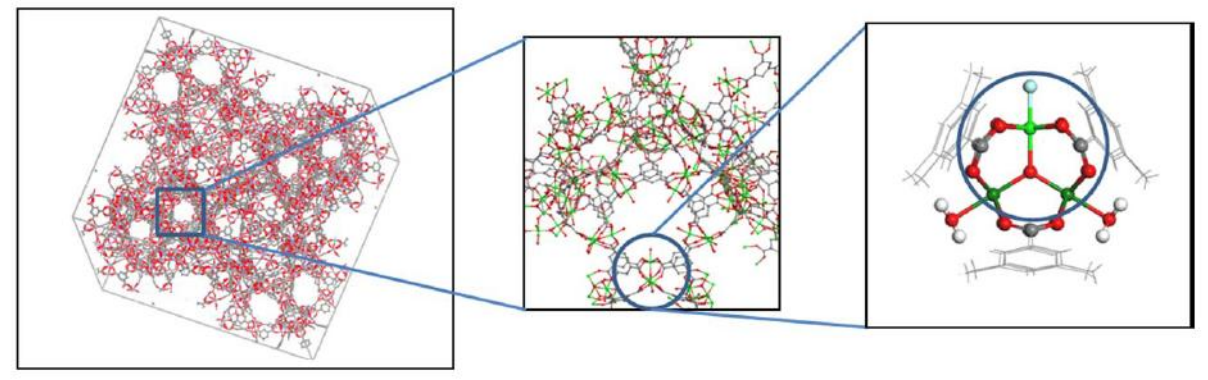

b

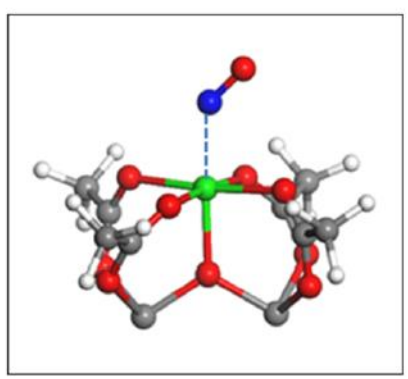

\begin{tabular}{|c|c|c|c|}
\hline 0 & - $\mathrm{Fe}$ (III) $\bigcirc \mathrm{C}$ & & C \\
\hline & Parameters & $\mathrm{Fe}(\mathrm{III}): \mathrm{d}^{5}$ & $\mathrm{Fe}(1): d^{e}$ \\
\hline & NO binding energy $(\mathrm{kJ} / \mathrm{mol})$ & -73.5 & -122.4 \\
\hline & distance $(\mathrm{Fe}-\mathrm{N})(\hat{\mathrm{A}})$ & 226 & 1.84 \\
\hline & angle (Fe-N-O) & $122^{\circ}$ & $140^{\circ}$ \\
\hline & charge transfer (NO) & 0.13 & -0.20 \\
\hline & distance $(\mathrm{N}-\mathrm{O})(\dot{\mathrm{A}})$ & 1.16 & 1.19 \\
\hline
\end{tabular}

Extended Data Figure 4: DFT model of MIL-100(Fe). a an extended cluster model taken from the MIL-100(Fe) crystal structure. b Fe small cluster model taken from the circle in the large cluster with adsorbed NO molecule; c Table: results on cluster model DFT calculations for NO binding on reduced MIL-100(Fe).

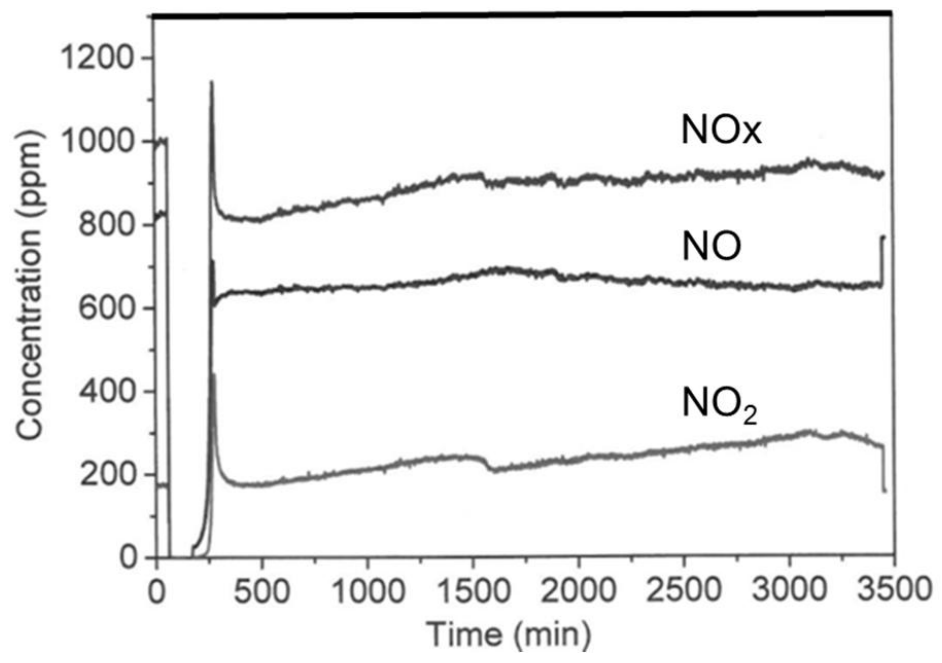

Extended Data Figure 5: NOx species profiles during a long test ( $>58$ hours). NOx species profiles in the gas phase after contact with partially reduced MIL-100(Fe) sample at $300 \mathrm{~K}$, gas feeding with $1000 \mathrm{ppm} \mathrm{NO}, 10 \% \mathrm{O}_{2}$ and $1 \% \mathrm{H}_{2} \mathrm{O}$ vapour. 


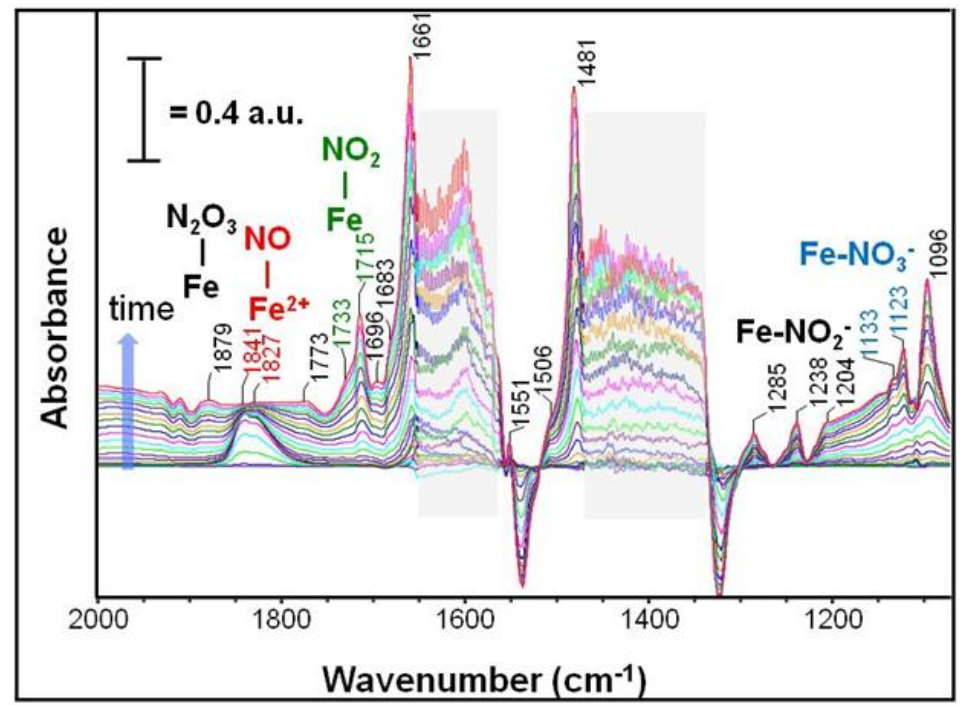

Extended Data Figure 6: IR spectral region of the sample, highlighting the presence of adsorbed N-containing species. Transmission FTIR spectra (after subtraction of the reference spectrum at $\mathrm{t}=0$ ) of the sample activated at $523 \mathrm{~K}$, then submitted to the reaction stream; spectra are collected at given intervals of time during the reaction. The main bands affected by the gas contact with the sample are reported, pointed and labelled. They correspond both to adsorbed species vibrational modes and perturbation of the structural features (carboxylate vibrations, whose stretches are covered by the grey zones).

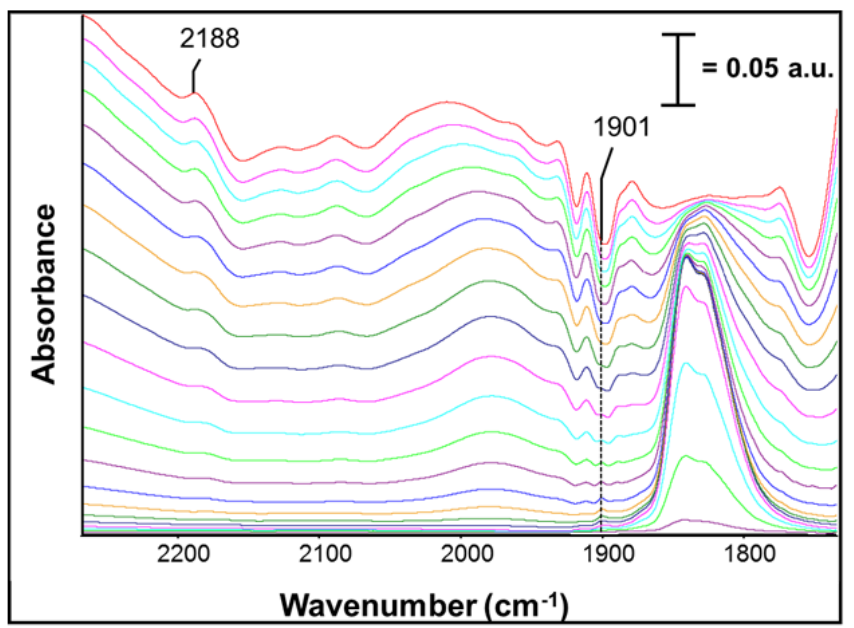

Extended Data Figure 7: highlighting the $\mathrm{NO}^{+}$vibration. Transmission FTIR spectra (after subtraction of the reference spectrum at $\mathrm{t}=0$ ) of the sample activated at $523 \mathrm{~K}$, then submitted to the reaction stream; spectra are collected at given intervals of time during the reaction. Zoom in the region $2300-1700 \mathrm{~cm}^{-1}$. 


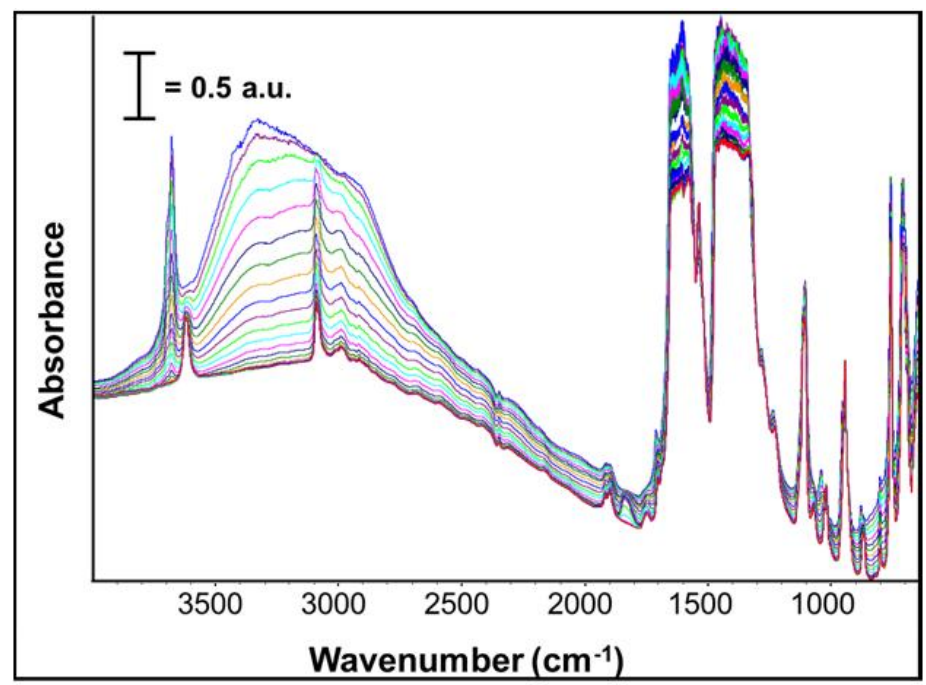

Extended Data Figure 8: Transmission FTIR direct spectra of MIL-100(Fe) in the MIDIR region. The sample was activated at $523 \mathrm{~K}$, then submitted to the reaction stream; spectra are collected at given intervals of time during the reaction.

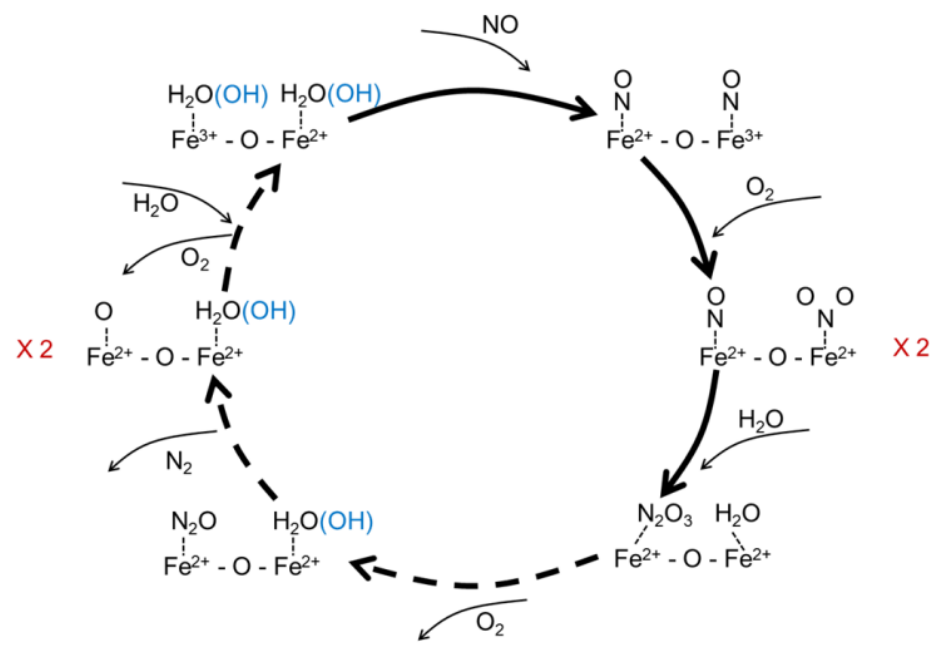

Extended Data Figure 9: Tentative reaction scheme for NO dissociation on MIL-100(Fe). Additional explanations about the scheme in more detail are made in Supplementary Information. The arrows in full line represent the (believed) main reaction steps and intermediates, as observed on the catalytic surface. The arrows in dotted line complete the catalytic reaction cycle according to models accepted in the literature (ref. 60 and 61). 


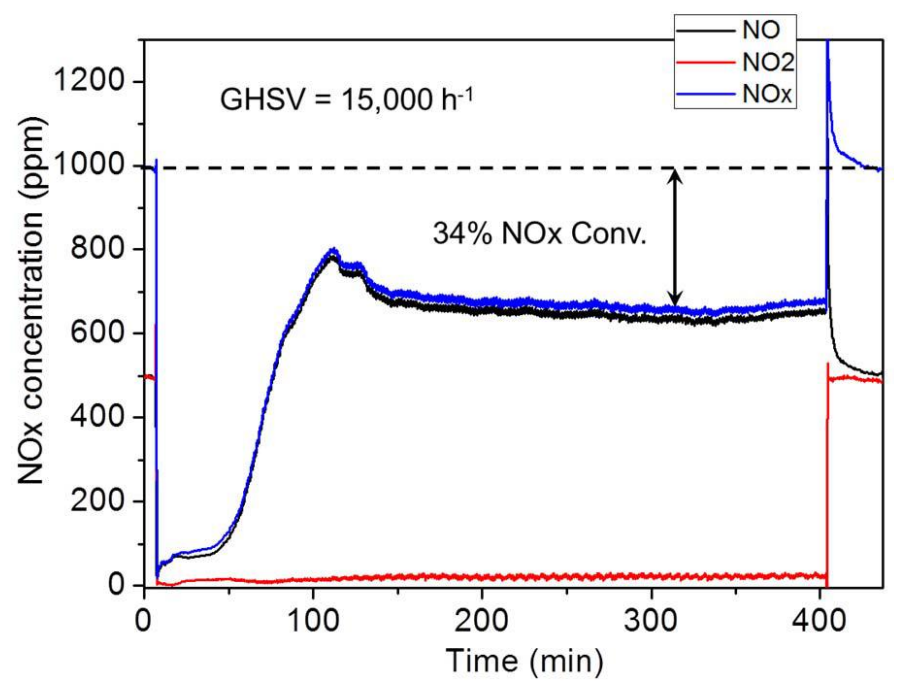

Extended Data Figure 10: effect of $\mathrm{NO}_{2}$ introduction. NOx concentrations (chemiluminescence profiles) after gas contact with the MIL-100(Fe) sample submitted to a

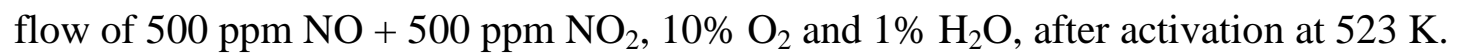

\section{Additional References}

${ }^{33}$ Treacy, M.M.J., Higgins, J.B. in Collection of Simulated XRD Powder Patterns for Zeolites, 4th ed., Elsevier 2001, and http:// www.iza-structure.org/databases/.

${ }^{34}$ Vimont, A. et al. Investigation of Acid Sites in a Zeotypic Giant Pores Chromium(III) Carboxylate. J. Am. Chem. Soc. 128, 3218-3227 (2006).

${ }^{35}$ Yoon, et al. Controlled Reducibility of a Metal-Organic Framework with Coordinatively Unsaturated Sites for Preferential Gas Sorption. Angew. Chem. Int. Ed. 49, 5949-5952 (2010).

${ }^{36}$ Liu, Y., et al. Assembly of metal-organic frameworks (MOFs) based on indium-trimer building blocks: A porous MOF with soc topology and high hydrogen storage. Angew. Chem. Int. Ed. 46, 3278-3283 (2007).

${ }^{37}$ O'Keeffe, M., Eddaoudi, M., Li, H.L., Reineke, T., Yaghi, O.M. Frameworks for extended solids: Geometrical design principles. J. Solid State Chem. 152, 3-20 (2000).

${ }^{38}$ Serre, C. et al. Utilisation d'un solide hybride cristallin poreux comme catalyseur de réduction d'oxydes d'azote et dispositifs, 106660/FR filed 28/05/2009; PCT/ FR2010/000402 (28/05/2010) ; WO2010136677.

${ }^{39}$ Whitfield, T.R., Wang, X., Liu, L., Jacobson, A.J. Metal-organic frameworks based on iron oxide octahedral chains connected by benzenedicarboxylate dianions. Solid Sta. Sci. 7, 10961103 (2005).

${ }^{40}$ Férey, G. \& Serre, C. Large breathing effects in three-dimensional porous hybrid matter: facts, analyses, rules and consequences. Chem. Soc. Rev. 38, , 1380-1399 (2009).

${ }^{41}$ Kitagawa, S. \& Uemura K. Dynamic porous properties of coordination polymers inspired by hydrogen bonds. Chem. Soc. Rev. 34, , 109-119 (2005).

${ }^{42}$ Horike, S., Shimomura, S., Kitagawa, S. Soft porous crystals. Nature Chem. 1, 695-704 (2009).

${ }^{43}$ Millange, F., Serre, C., Guillou, N., Férey, G., Walton, R.I. Structural effects of solvents on the breathing of metal-organic frameworks: An in situ diffraction study. Angew. Chem. Int. Ed. 47, 4100-4105 (2008).

${ }^{44}$ Delley, B. An all-electron numerical-method for solving the local density functional for polyatomic-molecules. J. Chem. Phys. 92, 508-517 (1990). 
${ }^{45}$ Delley, B. From molecules to solids with the DMol(3) approach. J. Chem. Phys. 113, 77567764 (2000).

${ }^{46}$ Kresse, G. \& Furthmüller, J. Efficient iterative schemes for ab initio total-energy calculations using a plane-wave basis set. Phys. Rev. B 54, 11169-11186 (1996).

${ }^{47}$ Henkelman, G., Arnaldsson, A., Jónsson, H. A fast and robust algorithm for Bader decomposition of charge density. Comput. Mater. Sci. 36, 354-360 (2006).

${ }^{48}$ Tkatchenko A. \& Scheffler, M. Accurate Molecular Van Der Waals Interactions from Ground-State Electron Density and Free-Atom Reference Data. Phys. Rev. Lett. 102, $\mathrm{n}^{\circ}$ 073005 (2009).

${ }^{49}$ Kresse, G. \& Joubert, D. From ultrasoft pseudopotentials to the projector augmented-wave method. Phys. Rev. B 59, 1758-1775 (1999).

${ }^{50}$ Grimme, S. Semiempirical GGA-type density functional constructed with a long-range dispersion correction. J. Comp. Chem. 27, 1787-1799 (2006).

${ }^{51}$ Lesage, T., Verrier, C., Bazin, P., Saussey, J., Daturi, M. Studying the NOx-trap mechanism over a Pt-Rh/Ba/ $/ \mathrm{Al}_{2} \mathrm{O}_{3}$ catalyst by operando FT-IR spectroscopy. Phys. Chem. Chem. Phys. 5, 4435-4440 (2003).

${ }^{52}$ Malpartida, I. et al. $\mathrm{CO}$ and $\mathrm{NO}$ adsorption for the IR characterization of $\mathrm{Fe}^{2+}$ cations in ferrierite: An efficient catalyst for $\mathrm{NOx} \mathrm{SCR}$ with $\mathrm{NH}_{3}$ as studied by operando IR spectroscopy. Catal. Today 149, 295-303 (2010).

${ }^{53}$ Rasmussen, S.B., Perez-Ferreras, S., Bañares, M.A., Bazin, P., Daturi, M. Does Pelletizing Catalysts Influence the Efficiency Number of Activity Measurements? Spectrochemical Engineering Considerations for an Accurate Operando Study. ACS Catal. 3, , , 86-94 (2013).

${ }^{54}$ Rasmussen, S.B., Perez-Ferreras, S., Bañares, M.A., Bazin, P., Daturi M. Does Pelletizing Catalysts Influence the Efficiency Number of Activity Measurements? Spectrochemical Engineering Considerations for an Accurate Operando Study. ACS Catal. 3, 86-94 (2013). ${ }^{55}$ Hadjiivanov, K.I. Identification of Neutral and Charged $\mathrm{N}_{\mathrm{x}} \mathrm{O}_{\mathrm{y}}$ Surface Species by IR Spectroscopy. Catal. Rev.-Sci. Eng. 42, 71-144 (2000).

${ }^{56}$ Lesage, T. et al. Operando FTIR study of NOx storage over a Pt/K/Mn/ $/ \mathrm{Al}_{2} \mathrm{O}_{3}-\mathrm{CeO}_{2}$ catalyst. Appl. Catal. B: Environmental 72, 166-177 (2007).

${ }^{57}$ Lei, J.P., Ju, H.X., Ikeda, O. Catalytic oxidation of nitric oxide and nitrite mediated by water-soluble high-valent iron porphyrins at an ITO electrode, J. Electroanalytical Chemistry 567, 331-338 (2004).

${ }^{58}$ Chen, H.-Y., El-Malki, E.M., Wang, X., van Santen, R.A., Sachtler, W.M.H. Identification of active sites and adsorption complexes in Fe/MFI catalysts for NOx reduction. J. Mol. Catal. A: Chem. 162, 159-174 (2000).

${ }^{59}$ Busca, G., Lorenzelli, V. Infrared study of the adsorption of nitrogen-dioxide, nitric-oxide and nitrous-oxide on hematite. J. Catal. 72, 303-313 (1981).

${ }^{60}$ Rémazeilles, C., Refait, $\mathrm{Ph}$. Fe(II) hydroxycarbonate $\mathrm{Fe}-2(\mathrm{OH})(2) \mathrm{CO}_{3}$ (chukanovite) as iron corrosion product: Synthesis and study by Fourier Transform Infrared Spectroscopy. Polyhedron 28, 749-756 (2009).

${ }^{61}$ Solans-Monfort, X., Branchadell, V., Sodupe, M. On the NO Decomposition by Cu-ZSM-5 through the $\mathrm{ZCu}\left(\mathrm{NO}_{2}\right)(\mathrm{NO})$ or $\mathrm{ZCu}\left(\mathrm{N}_{2} \mathrm{O}_{3}\right)$ Intermediates. J. Phys. Chem. B 106, 1372-1379 (2002).

${ }^{62}$ Aylor, A.W., Larsen, S.C., Reimer, J.A. Bell, A.T. An infrared study of NO decomposition over Cu-ZSM-5. J. Catal. 157, 592-602 (1995).

${ }^{63}$ Dupré, J. et al. Understanding the storage function of a commercial NOx-storage-reduction material using operando IR under realistic conditions. Appl. Catal. B: Environ. 160, 335-343 (2014). 
${ }^{64}$ Van de Voorde, B. et al. N/S-heterocyclic contaminant removal from fuels by the mesoporous metal-organic framework MIL-100: the role of the metal ion. J. Am. Chem. Soc. 135, 9849-9856 (2013).

${ }^{65}$ Llewellyn, P. et al. High uptakes of $\mathrm{CO}_{2}$ and $\mathrm{CH}_{4}$ in the mesoporous Metal-OrganicFrameworks MIL100 and MIL101. Langmuir 24, 7245-7250 (2008). 